\title{
Heat transfer of developing and fully developed flow in smooth horizontal tubes in the transitional flow regime
}

\author{
M. Everts and J. P. Meyer* \\ *Author for correspondence \\ Department of Mechanical and Aeronautical Engineering, University of Pretoria, Pretoria, 0002, \\ South Africa, E-mail: josua.meyer@up.ac.za
}

\section{Highlights}

- Flow regime nomenclature.

- Developing and fully developed transitional flow experimental data.

- The transitional flow regime of developing flow decreased with axial position.

- Free convection effects decreased the width of the transitional flow regime.

- Correlations to predict the start and end of the transitional flow regime.

\section{Abstract}

Limited experimental work has been done specifically focussing on how the heat transfer characteristics of developing flow in the transitional flow regime changes along the tube length, and how it compares with fully developed flow. The purpose of this study was therefore to experimentally investigate the heat transfer characteristics of developing and fully developed flow in smooth horizontal tubes in the transitional flow regime at a constant heat flux. An experimental set-up was designed, built and validated against literature. Two smooth circular test sections with inner diameters of $4 \mathrm{~mm}$ and $11.5 \mathrm{~mm}$, respectively, were used and the maximum length-to-diameter ratios were 1373 and 872, respectively. Heat transfer measurements were taken at Reynolds numbers between 700 and 10000 at different heat fluxes. The boundaries of the different flow regimes were defined mathematically, and terminology to define the transition characteristics were presented. It was found that the Reynolds number at which transition started was independent of axial position, and transition occurred at the same moment in time along the whole tube length. However, the end of transition was dependent on axial position and occurred earlier as the flow approached fully developed flow. Free convection effects affected both the start and end of the transitional flow regime, and caused the Reynolds number range of the transitional flow regime to decrease. Correlations were developed to determine the start and end of the transitional flow regime for developing and fully developed flow for mixed convection conditions. The transitional flow regime of developing flow was divided into three regions. In the first region, the width of the transitional flow regime decreased significantly with axial position and free convection effects were negligible. In region 2 , the width of the transitional flow 
regime decreased with both axial position and free convection effects. In the fully developed region, the width of the transitional flow regime was independent of axial position, but free convection effects caused it to decrease and even to become negligible. It was concluded that the heat transfer characteristics of developing flow in the transitional flow regime changes as the flow develops and differ significantly from fully developed flow.

\section{Graphical abstract}

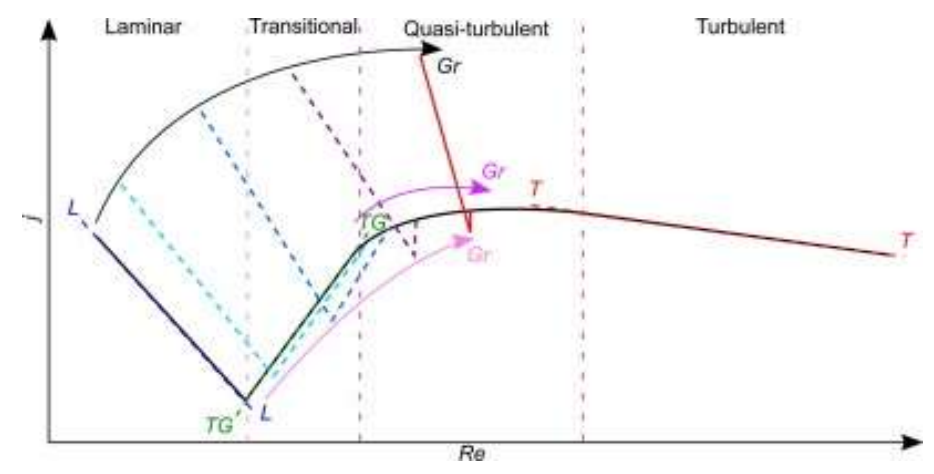

Keywords: Developing flow; fully developed flow; transitional; heat transfer; constant heat flux; forced convection; mixed convection

\section{Nomenclature}

A Area

$C_{p} \quad$ Constant-pressure specific heat

$D \quad$ Inner diameter

$D_{o} \quad$ Outer diameter

$E B$ Energy balance

$g$ Gravitational acceleration

Gr Grashof number

$G r^{*} \quad$ Modified Grashof number

$h \quad$ Average circumferential heat transfer coefficient

I Current

$i \quad$ Data point index

$j \quad$ Colburn $j$-factor

$j_{c r} \quad$ Colburn $j$-factor at $R e_{c r}$

$j_{q t} \quad$ Colburn $j$-factor at $R e_{q t}$

$k \quad$ Thermal conductivity

$L \quad$ Length

$M \quad$ Measurement or calculated value

$\dot{m} \quad$ Mass flow rate

$n \quad$ Number of thermocouples at station/ number of data points

$\mathrm{Nu} \quad$ Nusselt number

$\mathrm{Pr} \quad$ Prandtl number

$\dot{Q}_{e} \quad$ Electrical input rate
$\dot{Q}_{w} \quad$ Water heat transfer rate

$\dot{q} \quad$ Heat flux

$R_{\text {tube }}$ Thermal resistance

$R e \quad$ Reynolds number

$R e^{\prime} \quad$ Transitional flow inflection point

$R_{e r} \quad$ Critical Reynolds number

$R e_{q t} \quad$ Start of quasi-turbulent flow regime

$R e_{t} \quad$ Start of turbulent flow regime

$\Delta R e$ Width of transitional flow regime

$T$ Temperature

$T G_{j} \quad$ Transition gradient

$V \quad$ Voltage

$x \quad$ Distance from inlet

Greek letters

$\beta \quad$ Thermal expansion coefficient

$\varepsilon \quad$ Surface roughness

$\mu \quad$ Dynamic viscosity

$v \quad$ Kinematic viscosity

$\rho \quad$ Density

$\sigma \quad$ Standard deviation

Superscripts

- $\quad$ Average 


\begin{tabular}{ll}
\multicolumn{2}{l}{ Subscripts } \\
$b$ & Bulk \\
$c$ & Cross-section \\
cor & Correlation \\
exp & Experimental \\
$i$ & Inlet \\
$L$ & Laminar \\
$m$ & Mean \\
$o$ & Outer/outlet \\
$Q T$ & Quasi-turbulent
\end{tabular}

$s \quad$ Heat transfer surface

$T \quad$ Turbulent

$T G$ Transition gradient

Abbreviations

FCD Forced Convection

Developing region

FD Fully Developed region

MCD Mixed Convection

Developing region

\section{Introduction}

Design constraints, changes in operating conditions or equipment, corrosion and scaling, can cause heat exchangers to operate in, or close to, the transitional flow regime. In this flow regime, the flow alternates between laminar and turbulent flow and turbulent eddies occur in flashes, known as turbulent bursts. This might cause the pressure drop to increase an order of magnitude. Designers are thus usually advised to avoid this flow regime [1], since the flow is believed to be unstable and chaotic, and little design information is available [2].

According to a recent review paper by Meyer [2], the transitional flow regime has been mainly investigated by Professor Ghajar from Oklahoma State University and his co-workers, and by Professor Meyer from the University of Pretoria and his co-workers. Ghajar and coworkers used local temperature and pressure measurements along a tube length to investigate the effect of different inlet geometries and heating on the heat transfer coefficients and friction factors [3-12]. Although temperature measurements were taken at 31 stations along the test section, their investigations mainly focused on the fully developed flow results at $x / D=192$ (station 22). A constant heat flux boundary condition and different mixtures of distilled water and ethylene glycol were used, which resulted in high Prandtl numbers (up to 160).

Meyer and Olivier [13-16] used a constant surface temperature boundary condition and water as the test fluid, which resulted in significantly lower Prandtl numbers (approximately 7). Furthermore, the fluid was being cooled and not heated. As they considered the average measurements across a tube length, their data contained both developing (laminar and transitional flow regimes) and fully developed (turbulent flow regime) data. However, the focus was on the effect of inlet geometries and enhanced tubes. Meyer and co-workers also investigated transitional flow in nanofluids [17], micro-channels [18], annular flow [19] and tubes with twisted tape inserts [20]. 
Similar to Meyer and Olivier [13-16], Bertsche et al. [21] also investigated transitional flow using a constant surface temperature boundary condition (the fluid was also being cooled), using the average measurements along the tube length. As the maximum length-todiameter ratio of their test section was only 84.7, their data contained developing flow. However, the focus of their study was to compile an experimental database for heat transfer in the transitional flow regime using high Prandtl number fluids, and to compare it with the proposed correlation of Gnielinski [22].

Taler [23] gives a comprehensive overview of the available correlations in the transitional flow regime. The first correlation to predict the overall heat transfer coefficients in the transitional flow regime, was proposed by Hausen in 1959, however, many other studies found that their experimental heat transfer data in the transitional flow regime deviated from this equation [21]. Both Gnielinski [24] and Churchill [25] also developed correlations for developing and fully developed flow in the transitional flow regime. However, Tam and Ghajar [1] concluded that Gnielinski's and Churchill's correlations failed to accurately predict mixed convection data, since they did not address the effects of free convection superimposed on the main flow. Heat transfer correlations in the transitional flow regime were also developed by Ghajar and Tam [5], Yu-ting et al. [26] and Lu et al. [27], however, the Prandtl number ranges were limited to the test fluids that were used (mixtures of ethylene glycol and distilled water [5] and molten salt [26, 27]).

Gnielinski [22] proposed a method to determine the heat transfer coefficients in the transitional flow regime, by applying linear interpolation between laminar flow at a Reynolds number of 2300 and turbulent flow at a Reynolds number of 4000 . Although this method was tested using the numerical data of Abraham et al. [28], Gnielinski [22] mentioned that "no experimental data were found which have allowed checking the Nusselt numbers obtained by the calculation procedure outlined above in the region of linear interpolation, i.e., between $1000<R e<4000$ ". The lack of experimental data in the transitional flow regime is most probably the main reason for the limited understanding and little design information that is available for transitional flow.

Taler [23] proposed a new heat transfer correlation for transitional and turbulent flow in tubes. The correlation is valid for both a constant surface temperature and constant heat flux boundary condition and correlated well with experimental data and numerical data [23, 29]. The form of the correlation is such that at a Reynolds number of 2300 (where transition is assumed to start) the Nusselt number changes depending on whether the flow is hydrodynamically fully developed and thermally developing, or simultaneously 
hydrodynamically and thermally developing. However, according to Tam and Ghajar [1] the usually cited Reynolds number range of approximately 2300 to 10000 is only true for very steady and uniform entry flow with a rounded entrance. The Reynolds number range and heat transfer characteristics in the transitional flow regime are significantly affected by the inlet geometry, as well as free convection effects (as will be shown in this paper). Therefore, although this correlation accounted for developing flow, it is suited for forced convection conditions, rather than mixed convection conditions.

Although the transitional flow regime has been extensively investigated, the Reynolds number boundaries of the transitional flow regime were in general qualitatively and therefore relied on visual observations. The result is that the definition of the start and end of the transitional flow regime often relied on subjective decisions (which data points to consider as either laminar, transitional and turbulent), which made it challenging to compare transitional flow results of different studies. From the results in this study, as well as in Everts and Meyer [30], it follows that the transitional flow regime can be divided into two flow regimes, therefore four distinct flow regimes exist: laminar, transitional quasi-turbulent and turbulent. The upper part of the transitional flow regime has been previously referred to as the lowReynolds-number-end regime, however, due to the characteristics of this flow regime, it is proposed in this paper that it should be named the quasi-turbulent flow regime.

Ghajar and Tam [5] considered the start of the transitional flow regime as the location where the gradient of the Colburn $j$-factor lines (plotted as a function of Reynolds number) became zero, as it changed from negative to positive. The end of transition was considered as the location where the Colburn $j$-factor lines became parallel to the Colburn $j$-factors predicted by the fully developed turbulent correlations. Correlations were developed to predict the start and end of the transitional flow regime as a function of axial position, however, it did not account for free convection effects.

Meyer and Abolarin [20] investigated two methods to determine the boundaries of the transitional flow regime. The first method considered the standard deviation of the temperature measurements. It was found that the standard deviation in the laminar and turbulent flow regimes was approximately $0.1^{\circ} \mathrm{C}$, while it increased to $0.2^{\circ} \mathrm{C}$ in the transitional flow regime. The second method, which was also used by Ndenguma et al. [19], used three linear curve fits (on a log-log scale) of the Colburn $j$-factors as a function of Reynolds number, and was more convenient to implement. The Reynolds numbers at the intersection of the lines through the laminar and transitional data, and the transitional and turbulent data, were identified as the start and end of the transitional flow regime, 
respectively. Although both methods still relied on some subjective decisions, the authors found that reasonable results were obtained when the two methods were used to complement each other.

From literature it follows that Ghajar and co-workers broke the ground with investigating the effect of inlet geometry and heating on transition, making it possible for others, such as Meyer and co-workers, to follow. However, the focus of previous studies was on the effect of different inlet geometries, enhanced tubes, micro-channels, annular flow, nanofluids, and different Prandtl number fluids. Up to now, no experimental studies have been specifically devoted to the heat transfer characteristics of developing flow in the transitional flow regime, how it changes along the tube length, how it differs from fully developed flow, and how it is affected by free convection effects. Furthermore, the methods that were used to identify the boundaries of the transitional flow regime not only relied on subjective decisions, but also did not distinguish between the transitional and quasi-turbulent flow regimes.

The purpose of this study was to experimentally investigate the local heat transfer characteristics of developing and fully developed flow of water in smooth horizontal tubes with two tube diameters, at different heat fluxes. The fully developed work has been done by Ghajar and co-workers [3-12], with most of their experiments conducted with high Prandtl number fluids, but needed to be addressed again in this study for two reasons. Firstly, to expand the experimental database of heat transfer results in the transitional flow regime, and secondly, to illustrate the continuity of this work from developing to fully developed transitional flow. The main objectives were: (1) to quantify the boundaries of the different flow regimes mathematically, as well as to present terminology to define the transition characteristics, and (2) to investigate the influence of axial position, free convection and Prandtl number, on the heat transfer characteristics of developing flow in the transitional flow regime.

This paper forms part of a bigger study and is complimentary to papers published by Meyer and Everts [31] and Everts and Meyer [30, 32]. Meyer and Everts [31] investigated mixed convection laminar flow, as well as the effect of free convection on the laminarturbulent transition along the tube length. This paper investigates the heat transfer characteristics of developing and fully developed flow in the transitional flow regime, while the relationship between heat transfer and pressure drop in all flow regimes was investigated and quantified in Everts and Meyer [30]. The flow regime maps for not only fully developed flow but also developing flow, presented in Everts and Meyer [32] were developed using the results of this paper, as well as Meyer and Everts [31] and Everts and Meyer [30]. 


\section{Experimental set-up}

The details of the experimental set-up and test sections were discussed in detail in Meyer and Everts [31] and Everts [33], and will only be briefly discussed in this paper. The layout of the experimental set-up is shown in Fig. 1. The experimental set-up consisted of a closedloop system, which circulated water from a storage tank, through the test section and back to the storage tank, using two electronically controlled magnetic gear pumps.

As the mass flow rates varied over a wide range, Coriolis mass flow meters with different flow rate capacities were installed in parallel. The mass flow meter that would produce the most accurate mass flow rate measurements was selected during the experiments. Downstream of the mass flow meters, the fluid flowed through the flow-calming section to the test section and mixer, and then back into the storage tank.

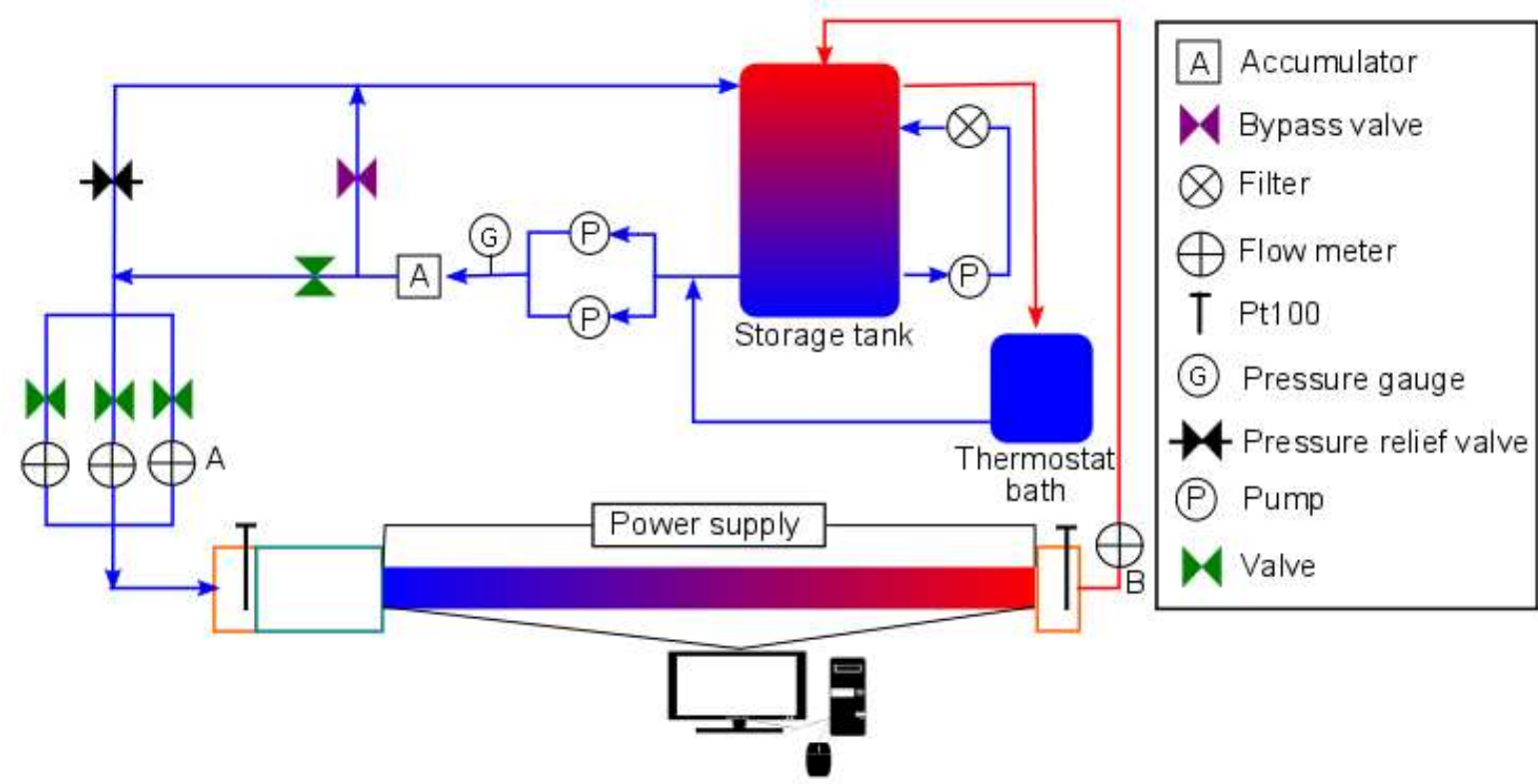

Fig. 1: Schematic representation of experimental set-up used to conduct heat transfer and pressure drop measurements. Water was circulated from the storage tank through the test section and back using two pumps.

\subsection{Flow-calming section}

A flow-calming section, similar to the one used by Ghajar and co-workers [3-11, 34, 35] was installed upstream of the test section to straighten the flow. The only difference was that the fluid first flowed through an additional $100 \mathrm{~mm}$ cavity filled with a soft nylon mesh (to mix the inlet flow to a uniform temperature), before it reached a Pt100 probe, where the average inlet temperature was measured. The acrylic tube had an inner diameter and length of $172 \mathrm{~mm}$ and $700 \mathrm{~mm}$, respectively, and an acetal disc was bolted to the inlet section to obtain a square-edged inlet. 


\subsection{Test sections}

Two test sections, with inner diameters of $11.5 \mathrm{~mm}$ and $4 \mathrm{~mm}$, respectively, were used to investigate the influence of tube diameter and heating method. The test sections are shown schematically in Fig. 2, while the details of the thermocouple stations and pressure taps were given in Meyer and Everts [31] and Everts and Meyer [30], respectively.
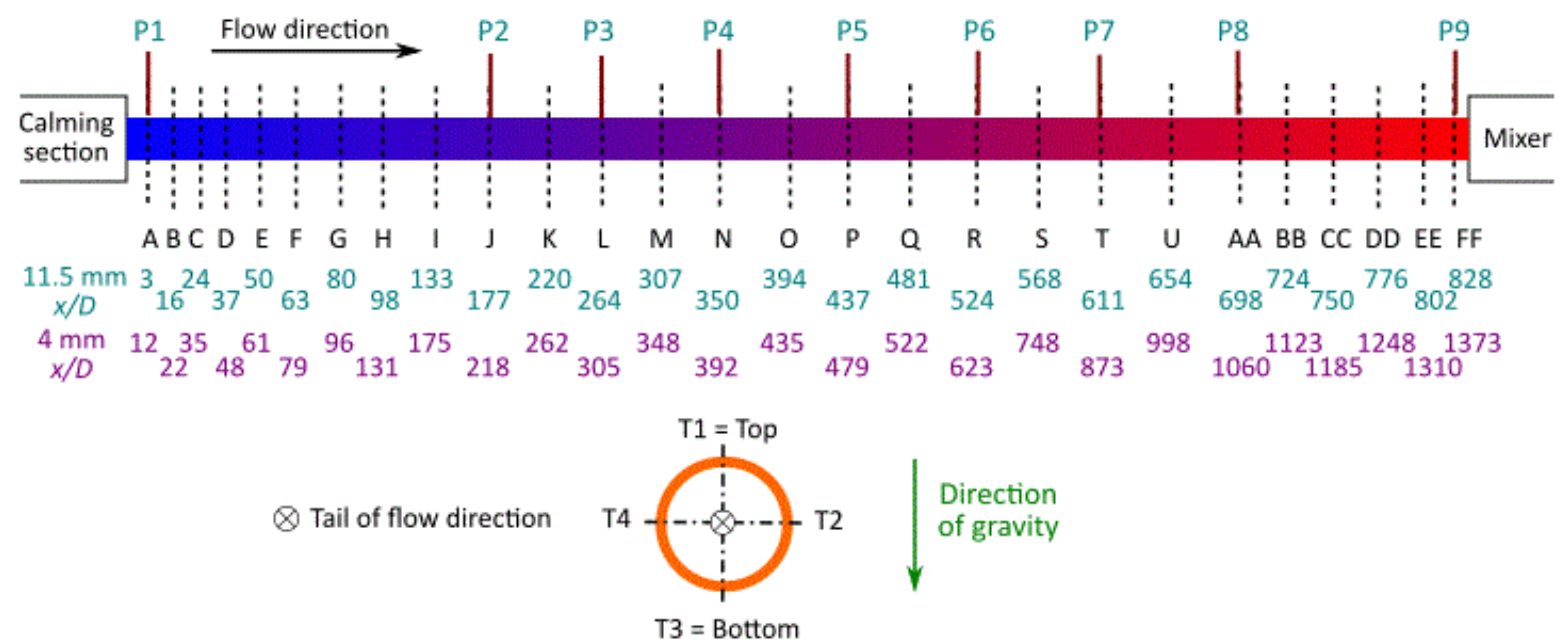

Fig. 2: Schematic representation of the test sections indicating the 27 thermocouples stations, A to FF, on the $11.5 \mathrm{~mm}$ and $4 \mathrm{~mm}$ test sections, as well as the nine pressure taps, P1 to P9, on the $11.5 \mathrm{~mm}$ test section. The $x / D$ values of the thermocouples stations of both test sections, are also given. A cross-sectional view of the test section is included to illustrate the four thermocouple positions spaced around the outside periphery of the tube.

The $11.5 \mathrm{~mm}$ test section was manufactured from a hard-drawn copper tube with an inside diameter of $11.52 \mathrm{~mm}$, outside diameter of $12.7 \mathrm{~mm}$, and a length of $9.81 \mathrm{~m}$. To prevent possible upstream flow effects from influencing the measurements at the last measuring station (station FF), $300 \mathrm{~mm}$ was allowed between the last measuring station (at $x=9.5 \mathrm{~m}$ ) and the mixer (at $x=9.8 \mathrm{~m}$ ). The $4 \mathrm{~mm}$ test section was manufactured from a seamless $316 \mathrm{~L}$ stainless steel tube with an inner and outer diameter of $4 \mathrm{~mm}$ and $6 \mathrm{~mm}$, respectively, and a length of $6 \mathrm{~m}$. However, temperature measurements were only taken across the first $5.5 \mathrm{~m}$, up to station FF. The remaining $500 \mathrm{~mm}$ between the last measuring station and mixer was, as with the $11.5 \mathrm{~mm}$ test section, to prevent possible upstream effects from influencing the measurements at the last thermocouple station.

The average surface roughness $(\varepsilon)$ of the $11.5 \mathrm{~mm}$ copper test section and $4 \mathrm{~mm}$ stainless steel test section was measured using a surface roughness tester, to be approximately $0.218 \mu \mathrm{m}$ and $0.138 \mu \mathrm{m}$, respectively. The relative surface roughness $(\varepsilon / D)$ was thus approximately $1.89 \times 10^{-5}$ and $3.45 \times 10^{-5}$, and for all practical purposes, both tubes can be considered as being smooth. The total length of the $11.5 \mathrm{~mm}$ and $4 \mathrm{~mm}$ test sections provided maximum length-to-inside diameter ratios $(x / D)$ of 828 and 1373 , respectively, 
while previous investigations by Ghajar and co-workers $[3-5,7,8,10,11]$ and Meyer and Olivier [13] had maximum values of 400 and 350, respectively. The test sections were thus 2-4 times longer than was in previous studies.

T-type thermocouples with a wire diameter of $0.25 \mathrm{~mm}$ and accuracy of $0.1{ }^{\circ} \mathrm{C}$ were used to measure the surface temperatures at 27 selected axial positions on both test sections. The thermocouple stations were spaced closer to each other near the inlet of the test section to accurately obtain the temperature profile of developing flow, while the thermocouple stations were spaced further apart on the rest of the test section where the flow was expected to be fully developed. To compare the developing heat transfer results in the $4 \mathrm{~mm}$ and $11.5 \mathrm{~mm}$ test sections, the same non-dimensional axial positions were used on both test sections for $x / D<524$. As the diameter of the $4 \mathrm{~mm}$ test section was 2.88 times smaller than the $11.5 \mathrm{~mm}$ test section, the maximum length-to-inside diameter ratio $(x / D)$ was 1.66 times larger than that of the $11.5 \mathrm{~mm}$ test section. To obtain sufficient heat transfer results in the remaining part of the $4 \mathrm{~mm}$ test section, the thermocouples were located at $500 \mathrm{~mm}$ intervals for $524<x / D<873$, and at $250 \mathrm{~mm}$ intervals for $873<x / D<1373$.

To investigate possible circumferential temperature distributions caused by free convection effects along the tube length, four thermocouples (spaced $90^{\circ}$ apart around the periphery) were used at each thermocouple station on the $11.5 \mathrm{~mm}$ test section, and on the $4 \mathrm{~mm}$ test section for $x / D<524$. The remaining thermocouple stations on the $4 \mathrm{~mm}$ test section contained thermocouples at the top and bottom of the test section, while the third thermocouple alternated between the left (T4 in Fig. 2) and right (T2 in Fig. 2) of the test section.

The thermocouples were soldered onto the $11.5 \mathrm{~mm}$ copper test section in a $0.3 \mathrm{~mm}$ indentation. As the wall thickness of the $4 \mathrm{~mm}$ stainless steel tube was $1 \mathrm{~mm}$, the thermocouples were glued into $0.5 \mathrm{~mm}$ indentations using a thermal adhesive with a thermal conductivity of $9 \mathrm{~W} / \mathrm{m} . \mathrm{K}$. A $3 \mathrm{D}$ printed jig was used to ensure that the holes were drilled to the same depth. The thermocouples of both test sections were calibrated in-situ to an accuracy of $0.1^{\circ} \mathrm{C}$, by pumping water from the thermostat-controlled bath through the flowcalming section, test section and mixer, and back into the thermostat-controlled bath. Reference temperatures were obtained using Pt100 probes at the inlet of the flow-calming section, at the outlet of the mixer and in the thermostat-controlled bath. The temperature of the thermostat-controlled bath was varied between $20^{\circ} \mathrm{C}$ and $60^{\circ} \mathrm{C}$. 
Two different heating methods were used in this study, because of the availability of equipment. To obtain a constant heat flux boundary condition in the $11.5 \mathrm{~mm}$ copper test section, four constantan wires (connected in parallel) with a diameter of $0.38 \mathrm{~mm}$ were coiled around the test section. A constant heat flux boundary condition was obtained in the $4 \mathrm{~mm}$ stainless steel test section, by passing current through the tube wall. The test section was electrically insulated with Kapton film before it was thermally insulated. Both test sections were thermally insulated with $120 \mathrm{~mm}$ thick Armaflex insulation with a thermal conductivity of $0.034 \mathrm{~W} / \mathrm{m} . \mathrm{K}$. The maximum heat loss was estimated with one-dimensional conduction heat transfer calculations to be less than $3 \%$ in both test sections. When axial heat conduction in the tube wall is significant, it needs to be taken into consideration when calculating the local heat transfer coefficients [36, 37]. However, using the criteria of Maranzana et al. [38], axial heat conduction was assumed to be negligible in both test sections, since the axial heat conduction number was orders of magnitude less than 0.01 .

\subsection{Mixer}

During laminar flow measurements, significant cross-sectional temperature gradients in the radial and tangential directions developed throughout the test section. Therefore, to obtain uniform tube outlet temperatures, a mixer was inserted after the test section to mix the water exiting the test section. The purpose of the mixer was twofold: to house the splitter plates, as well as to house a Pt100 probe that was used to measure the average outlet water temperatures. The mixer design was based on work done by Bakker et al. [39], who investigated laminar flow in static mixers with helical splitter plates.

\subsection{Experimental procedure}

Details of the experimental procedure were given in Meyer and Everts [31]. In the laminar flow regime, at very low Reynolds numbers, approximately 30 minutes was required to reach steady-state conditions. As the mass flow rate was increased, the time required for steady-state decreased to 20 minutes. Although the mass flow rates in the transitional flow regime were greater than in the laminar flow regime, up to 1 hour was required to reach steady-state due to the mass flow rate and temperature fluctuations inside the tube. In the quasi-turbulent and turbulent flow regimes, approximately 15 minutes was required for steady-state. After steady-state had been reached, 200 measuring points (temperature, pressure and mass flow rate) were captured at a frequency of $10 \mathrm{~Hz}$. This has been repeated several times and similar results were obtained, therefore the sampling time and frequency 
did not affect the periodic and quasi-periodic behaviour of the flow in the transitional and quasi-turbulent flow regimes.

\subsection{Test matrix}

Experiments conducted at different mass flow rates and heat fluxes in the two test sections of $11.5 \mathrm{~mm}$ and $4 \mathrm{~mm}$, are summarised in Table 1 . The test matrix consisted of 1046 mass flow rate measurements, 89459 temperature measurements and 2906 pressure drop measurements.

Table 1: Experimental test matrix generated with water in the $4 \mathrm{~mm}$ and $11.5 \mathrm{~mm}$ test sections.

\begin{tabular}{cccccc}
\hline $\begin{array}{c}\text { Test } \\
\text { section }\end{array}$ & $\begin{array}{c}\text { Heat flux } \\
{\left[\mathrm{kW} / \mathrm{m}^{2}\right]}\end{array}$ & $\begin{array}{c}\text { Reynolds } \\
\text { number range }\end{array}$ & $\begin{array}{c}\text { Mass flow rate } \\
\text { measurements }\end{array}$ & $\begin{array}{c}\text { Temperature } \\
\text { measurements* }\end{array}$ & $\begin{array}{c}\text { Pressure drop } \\
\text { measurements }\end{array}$ \\
\hline \multirow{5}{*}{$11.5 \mathrm{~mm}$} & 0 & $507-14968$ & 178 & 16535 & 1095 \\
& 0.06 & $303-1793$ & 28 & 1344 & - \\
& 1 & $597-9280$ & 69 & 7521 & 552 \\
& 2 & $894-9376$ & 62 & 6758 & 496 \\
& 6.5 & $1061-9509$ & 55 & 5995 & 440 \\
& 8 & $460-9630$ & 111 & 5382 & 111 \\
$4 \mathrm{~mm}$ & 9.5 & $470-9600$ & 103 & 4944 & 103 \\
& 0.5 & $913-3303$ & 32 & 5232 & 109 \\
\hline & 1 & $965-6021$ & 67 & 7456 & - \\
& 2 & $947-7176$ & 66 & 7128 & - \\
& 4 & $1005-6963$ & 62 & 6696 & - \\
\hline
\end{tabular}

*3 or 4 thermocouples per station

\section{Data reduction}

As a constant heat flux boundary condition was applied to the test section, the average axial temperature of the water increased linearly. The mean fluid temperature, $T_{m}$, at a specific tube location, $x$, was obtained using a linear temperature distribution between the measured inlet, $T_{i}$, and measured outlet, $T_{o}$, temperatures of the fluid over the tube length, $L$ :

$$
T_{m}=\left(\frac{T_{o}-T_{i}}{L}\right) x+T_{i}
$$

The bulk fluid temperature, $T_{b}$, along a tube length, $L(x)$, measured from the inlet of the test section, was calculated as: 


$$
T_{b}=\left(\frac{T_{o}-T_{i}}{L}\right) \frac{L(x)}{2}+T_{i}
$$

The properties of water (density, $\rho$, dynamic viscosity, $\mu$, thermal conductivity, $k$, specific heat, $C_{p}$, Prandtl number, $\operatorname{Pr}$, and thermal expansion coefficient, $\beta$ ) were determined using the thermophysical correlations for liquid water [40] at the bulk fluid temperature for the average properties, and at the mean fluid temperature for the local properties at a specific point $x$, measured from the inlet of the test section.

The Reynolds number, $R e$, was calculated as:

$$
R e=\frac{\dot{m} D}{\mu A_{c}}
$$

where $\dot{m}$ was the measured mass flow rate, $D$ was the measured inner-tube diameter, $\mu$ was the dynamic viscosity, and $A_{\mathrm{c}}$ the cross-sectional area of the test section $\left(A_{c}=\pi / 4 D^{2}\right)$.

The electrical input rate $\left(\dot{Q}_{e}=V I\right)$ remained constant, resulting in a constant heat flux. The heat transfer rate to the water, $\dot{Q}_{w}$, was determined from the measured mass flow rate, measured inlet and outlet temperatures of the water, and the specific heat which was calculated at the bulk fluid temperature:

$$
\dot{Q}_{w}=\dot{m} C_{p}\left(T_{o}-T_{i}\right)
$$

The heat transfer rate to the water, $\dot{Q}_{w}$, was continuously monitored by comparing it to the electrical input rate, $\dot{Q}_{e}$, which should ideally be equal since the test section was well insulated. The energy balance, $E B$, which ideally should be as close as possible to zero, was determined as:

$$
E B=\left|\frac{\dot{Q}_{e}-\dot{Q}_{w}}{\dot{Q}_{e}}\right| * 100=\left|\frac{V I-\dot{m} C_{p}\left(T_{o}-T_{i}\right)}{V I}\right| * 100
$$

The average energy balance of all the experiments that were conducted was less than $3 \%$, which was in good agreement with the calculations estimating the heat losses through the insulation material.

The heat flux, $\dot{q}$, on the inside of the tube wall was determined from the heat transfer rate to the water, $\dot{Q}_{w}$, and the inner surface area, $A_{s}$, of the test section along the heated length, $L$ : 


$$
\dot{q}=\frac{\dot{Q}_{w}}{A_{s}}=\frac{\dot{m} C_{p}\left(T_{o}-T_{i}\right)}{\pi D L}
$$

The heat transfer rate to the water was used to determine the heat flux, since it was regarded as more accurate than the electrical input rate. As the energy balance was not zero, and some losses did occur to the ambient air, the electrical input rate was always slightly higher than the heat transfer rate to the water.

The average of the four (or three) temperature measurements at a station was used as the average outer surface temperature, $T_{s, o}$, at a specific thermocouple station:

$$
T_{s, o}=\frac{T_{1}+T_{2}+\cdots+T_{n}}{n}
$$

The thermal resistance, $R_{\text {tube }}$, across the tube wall was calculated using the following equation:

$$
R_{\text {tube }}=\frac{\ln \left(\frac{D_{o}}{D}\right)}{2 \pi k L}
$$

where $D_{o}$ and $D$ were the measured outside and inside diameters of the tube.

The thermal conductivity of copper is $401 \mathrm{~W} / \mathrm{m} . \mathrm{K}$, while the thermal conductivity of $316 \mathrm{~L}$ stainless steel is only $16.3 \mathrm{~W} / \mathrm{m} . \mathrm{K}$. The temperature differences across the tube wall, $\Delta T$, was calculated using Eqs. (8) and (9), since the thermal resistance and heat input were known:

$$
\Delta T=\dot{Q}_{w} R_{t u b e}
$$

The thermal resistance in the $11.5 \mathrm{~mm}$ tube was calculated to be $4.05 \times 10^{-6 \circ} \mathrm{C} / \mathrm{W}$, as the wall thickness was $0.6 \mathrm{~mm}$. Therefore, the temperature difference across the tube wall was approximately $0.004^{\circ} \mathrm{C}$ when the maximum heat input $\left(3 \mathrm{~kW} / \mathrm{m}^{2}\right)$ was applied to the test section. The negligible temperature difference led to the assumption that the temperature on the inside surface of the test section was equal to the temperature measurement on the outside surface of the test section, since the temperatures in general could only be measured to an accuracy of $0.1^{\circ} \mathrm{C}$. It was therefore assumed that the surface temperatures, determined from Eq. (7), was the average surface temperature on the inside of the tube at a thermocouple station in the $11.5 \mathrm{~mm}$ test section. 
The thermal resistance in the $4 \mathrm{~mm}$ stainless steel tube was calculated to be $3.63 \times 10^{-}$ ${ }^{4} \mathrm{C} / \mathrm{W}$, which is two orders of magnitude more than in the $11.5 \mathrm{~mm}$ copper tube. Although the thermocouples in the $4 \mathrm{~mm}$ test section were placed in an $0.5 \mathrm{~mm}$ deep indentation in the tube wall, the temperature difference across the remaining $0.5 \mathrm{~mm}$ was approximately $0.2^{\circ} \mathrm{C}$ when the maximum heat input $\left(8 \mathrm{~kW} / \mathrm{m}^{2}\right)$ was applied to the test section. As this was not negligible, the temperature difference calculated using Eq. (9) was subtracted from the measured surface temperatures (Eq. (7)), to obtain the inner surface temperatures, $T_{s}$, of the $4 \mathrm{~mm}$ test section:

$$
T_{s}=T_{s, o}-\Delta T=T_{s, o}-\dot{Q}_{w} R_{t u b e}
$$

The average surface temperature of the test section, $\bar{T}_{s}$, was calculated from all the temperature measurements on the test section, using the trapezoidal rule:

$$
\bar{T}_{S}=\frac{1}{L} \int_{0}^{L} T_{S}(x) d x
$$

When free convection effects are significant, temperature variations exist along the circumference of the test section. The heat transfer coefficients along the circumference can therefore be calculated as an angle function [41]. However, for this study, the average circumferential temperature was used (Eq. (7)), therefore the average circumferential heat transfer coefficients, $h$, were determined from the following equation, since the heat flux, $\dot{q}$, surface temperature, $T_{s}$, and mean fluid temperature, $T_{m}$, were known:

$$
h=\frac{\dot{q}}{\left(T_{s}-T_{m}\right)}
$$

The Nusselt numbers, $\mathrm{Nu}$, were determined from the heat transfer coefficients as follows:

$$
N u=\frac{h D}{k}
$$

The heat transfer results were also investigated in terms of the Colburn $j$-factors, to account for the variation in the Prandtl number:

$$
j=\frac{N u}{\operatorname{RePr}^{\frac{1}{3}}}
$$


The Grashof numbers, $G r$, were determined using the following equation:

$$
G r=\frac{g \beta\left(T_{s}-T_{m}\right) D^{3}}{v^{2}}
$$

where $9.81 \mathrm{~m} / \mathrm{s}^{2}$ was used for the gravitational acceleration, $g$, and the kinematic viscosity was obtained from the density and dynamic viscosity $(v=\mu / \rho)$. The modified Grashof numbers, $G r^{*}$, which are a function of heat flux instead of temperature difference, were the product of the Grashof numbers and Nusselt numbers and were determined as follows:

$$
G r^{*}=G r N u=\frac{g \beta \rho \dot{q} D^{4}}{v^{2} k}
$$

Eqs. (12) - (16) were for the local values at a specific axial position along the tube length. The average values along a tube length, $L(x)$, measured from the inlet of the test section, were obtained by using the bulk fluid temperature (Eq. (2)) and average surface temperature (Eq. (11)), instead of the mean fluid temperature (Eq. (1)) and local surface temperature (Eq. (10)).

In general, the percentage error of a measurement or calculated value $(M)$ was determined as \%error $=\left|M_{\text {exp }}-M_{c o r}\right| M_{c o r} \times 100$. The average percentage error was taken as the average of the absolute errors of the data points.

The method suggested by Dunn [42] was used to calculate the uncertainties of the parameters obtained in the data reduction. All uncertainties were calculated within a $95 \%$ confidence interval and the uncertainty analysis details are given in Everts [33]. The Reynolds number uncertainties were approximately $1.5 \%$ in the laminar and turbulent flow regimes, and increased to $2 \%$ in the transitional flow regime due to the mass flow rate fluctuations that occurred in this flow regime. The laminar forced convection Nusselt number uncertainties were less than $10 \%$, while the laminar mixed convection uncertainties were less than 5\% and decreased with increasing heat flux. In the transitional flow regime, the uncertainties increased to approximately $10 \%$ (depending on the heat flux), due to the temperature fluctuations. The Nusselt number uncertainties in the turbulent flow regime increased with increasing Reynolds number and the average Nusselt number uncertainty at a Reynolds number of 6000 was $13 \%$. 


\section{Validation}

Extensive validation experiments were conducted and the details are given in Everts [33]. The heat transfer validation consisted of local laminar Nusselt number validations for forced and mixed convection conditions, as well as average laminar and turbulent Nusselt number validations.

It was very challenging to obtain forced convection conditions in macro tubes. The average fully developed Nusselt number $(50<x / D<827)$ in the $11.5 \mathrm{~mm}$ test section at a Reynolds number of 941 and heat flux of only $60 \mathrm{~W} / \mathrm{m}^{2}$, was found to be 4.75 . This was within $8.9 \%$ of the theoretical value of 4.36 for fully developed forced convection laminar flow. Forced convection conditions at a Reynolds number of 965 in the $4 \mathrm{~mm}$ test section were obtained at a heat flux of $1 \mathrm{~kW} / \mathrm{m}^{2}$. The average Nusselt number between $x / D=307$ and $x / D=1373$ was 4.5 , which was within $3.4 \%$ of the theoretical fully developed forced convection Nusselt number of 4.36. The results in both test sections also correlated well with the correlation of Shah and London [43], with an average deviation of $19 \%$ in the $11.5 \mathrm{~mm}$ test section, while the deviation between $x / D=567$ and $x / D=724$ was less than $3 \%$. An average deviation of $6 \%$ was obtained in the $4 \mathrm{~mm}$ test section, while the deviation between $x / D=307$ and $x / D=1373$ was $1.7 \%$.

The local laminar Nusselt numbers in the $11.5 \mathrm{~mm}$ and $4 \mathrm{~mm}$ test sections for mixed convection conditions, were compared to the correlation of Morcos and Bergles [44], which is valid for fully developed flow. The results correlated well with an average deviation of $6 \%$ between $x / D=37$ and $x / D=827$ in the $11.5 \mathrm{~mm}$ test section, and an average deviation of $4 \%$ between $x / D=79$ and $x / D=1373$ in the $4 \mathrm{~mm}$ test section.

The average laminar Nusselt numbers in the $11.5 \mathrm{~mm}$ and $4 \mathrm{~mm}$ test sections correlated well with the correlation of Morcos and Bergles [44] with an average deviation of $2 \%$ and $4 \%$, respectively. Furthermore, the average turbulent Nusselt numbers in the $11.5 \mathrm{~mm}$ and $4 \mathrm{~mm}$ test sections correlated very well with the correlation of Ghajar and Tam [5], with an average deviation of less than $1 \%$ and $3.2 \%$, respectively. The results also correlated well with the correlation of Gnielinski [24] and the average deviation was 5\% and less than $1 \%$ in the $11.5 \mathrm{~mm}$ and $4 \mathrm{~mm}$ test sections, respectively.

\section{Flow regime nomenclature}

Although the Reynolds number boundaries between the laminar and transitional flow regimes have been described in literature, the descriptions were in general qualitatively and therefore relied on visual observations, which are subjective. Furthermore, in most of these 
cases, no clear distinction between the transitional and quasi-turbulent flow regimes was made. When large databases are collected, it is challenging to objectively and consistently identify the different boundaries. The result is that different transition outcomes can be generated from the same data. Therefore, for the purposes of this study, the boundaries between the flow regimes, as well as terminology to define transitional flow characteristics, were quantified mathematically, in order to be able to determine it computationally.

The boundaries of the transitional flow regime $\left(R e_{c r}\right.$ and $\left.R e_{q t}\right)$ can be identified from the standard deviation of the temperature and mass flow rate measurements (see for example Fig. 9 and Fig. 10). However, this cannot be used to identify the start of the turbulent flow regime, $R e_{t}$, since there is not a significant difference between the standard deviations of the mass flow rate and temperature measurements in the quasi-turbulent and turbulent flow regimes. As the heat transfer results were presented and investigated in terms of Nusselt numbers and Colburn $j$-factors, it was used to define the boundaries of the different flow regimes, since these parameters are generally available (when the experimental data of other studies are analysed and investigated), while the temperature and mass flow rate measurements are not necessarily available. The results in terms of the Nusselt numbers and Colburn $j$-factor lines were used complimentary, as it was found that some boundaries were easier to identify using the Nusselt number lines, and others using the Colburn $j$-factor lines.

Fig. 3 is a schematic representation of the flow regimes in terms of the Nusselt numbers (Fig. 3(a)) and Colburn $j$-factors (Fig. 3(b)) as a function of Reynolds number. The boundaries of the different flow regimes $\left(R e_{c r}, R e_{q t}\right.$ and $\left.R e_{t}\right)$, are indicated on the $x$-axis. Furthermore, the gradients of the Nusselt number $(d N u / d R e)$ and Colburn $j$-factor $(d j / d R e)$ lines in the different flow regimes, are defined along the $L-L, T G-T G, Q T-Q T$ and $T-T$ lines. 


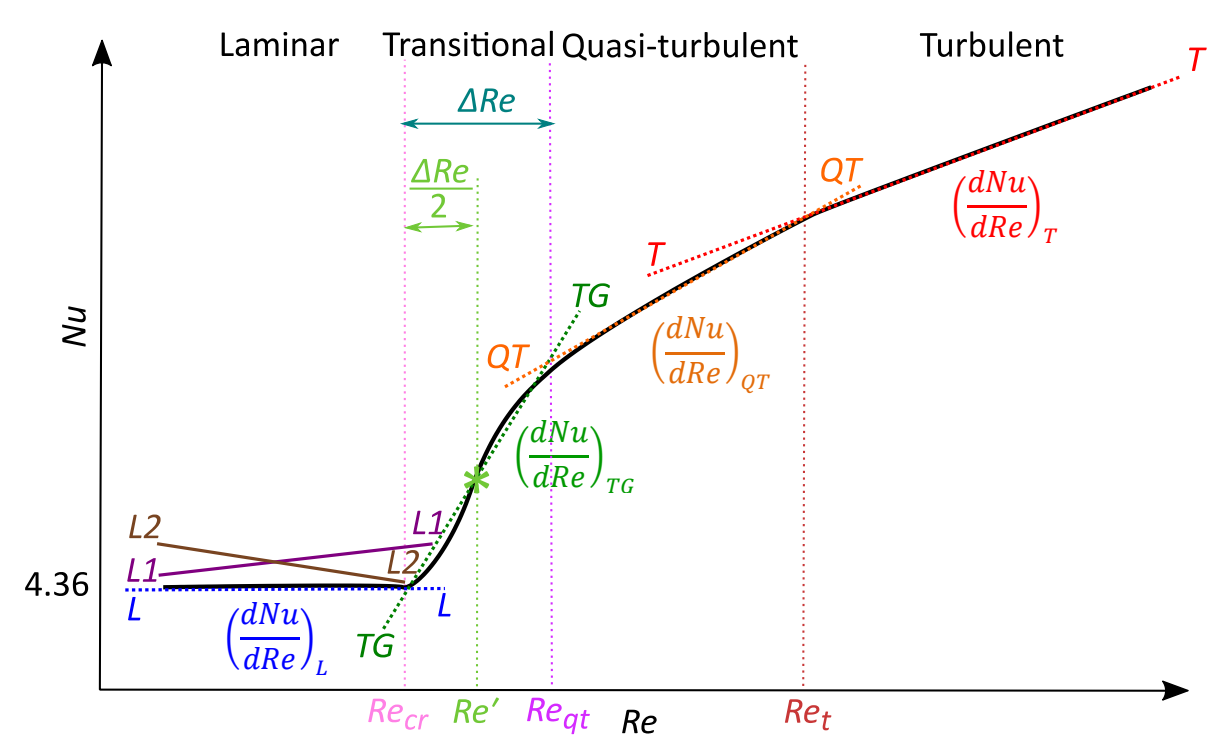

(a)

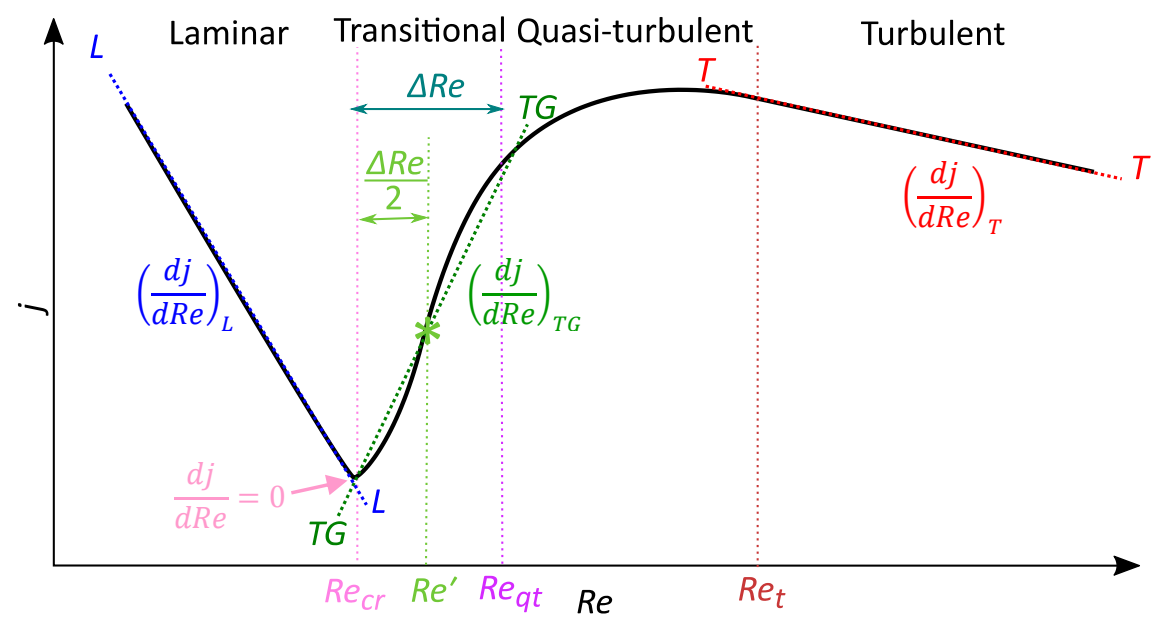

(b)

Fig. 3: Schematic representation of the different flow regimes for in terms of (a) Nusselt number and (b) Colburn j-factor as a function of Reynolds number.

\subsection{Flow regime boundaries}

5.1.1 Start of the transitional flow regime, $R e_{c r}$

The start of the transitional flow regime (and end of the laminar flow regime), $R e_{c r}$, was defined similarly to Ghajar and Tam [5] as:

$$
R e=R e_{c r} \text { when: }\left(\frac{d j}{d R e}\right)_{i-2: i}=0
$$

The notation $i-2: i$ indicates that at an arbitrary point $i$, the gradient was obtained using the three data points at $\operatorname{Re}(i-2), \operatorname{Re}(i-1)$ and $\operatorname{Re}(i)$, for increasing Reynolds numbers. We have experimented using less and more data points, but have found that three data points gave in general best results. Fig. 4 contains the Colburn $j$-factor gradients, $d j / d R e$, as a function of 
Reynolds number at $x / D=98$ and a heat flux of $3 \mathrm{~kW} / \mathrm{m}^{2}$ in the $11.5 \mathrm{~mm}$ test section. From this figure it follows, that the critical Reynolds number is at 2540 , where the gradient changed from negative (laminar flow) to positive (transitional flow).

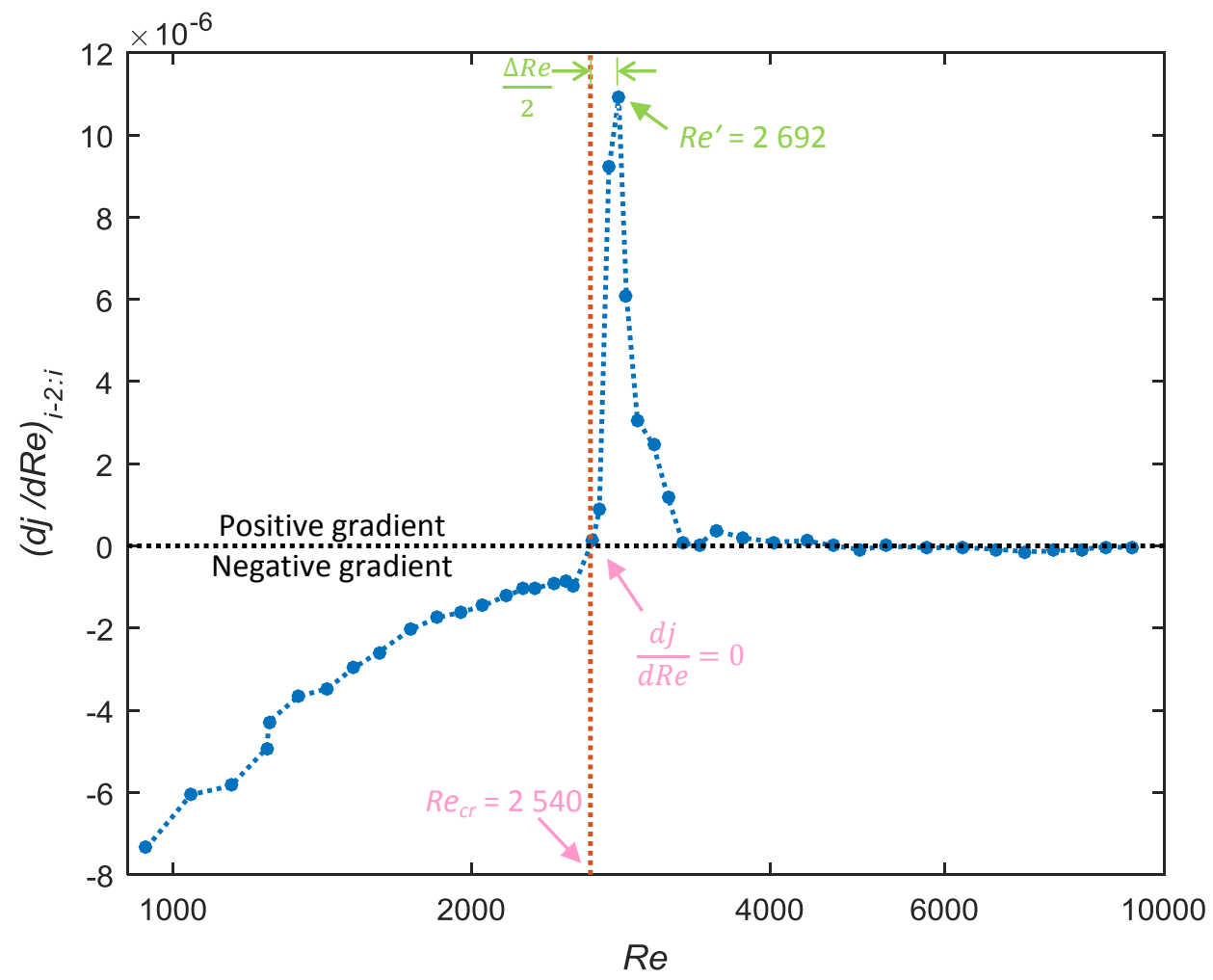

Fig. 4: Colburn $j$-factor gradient as a function of Reynolds number to identify the start of the transitional flow regime at $x / D=98$ and a heat flux of $3 \mathrm{~kW} / \mathrm{m}^{2}$ in the $11.5 \mathrm{~mm}$ test section.

\subsubsection{Start of the quasi-turbulent flow regime, $R e_{q t}$}

The end of transition, and the start of the quasi-turbulent flow regime $\left(R e_{q t}\right)$, was not as clear and easy to identify, as the start of transition. This challenge also has implications on accurately identifying the start of the turbulent flow regime $\left(R e_{t}\right.$ in Section 5.1.3). This possibly explains why, in literature, the quasi-turbulent flow regime is often regarded as part of either the transitional or turbulent flow regimes. However, as was found by Everts and Meyer [30] and will be shown in this paper, the flow characteristics and heat transfer coefficients in the quasi-turbulent flow regime are unique and not exactly the same as either the transitional or turbulent flow regimes. As the flow characteristics are similar to that of turbulent flow, although the flow is not fully turbulent yet, this flow regime was named quasi-turbulent. The start of the quasi-turbulent flow regime was defined as: 


$$
R e=R e_{q t} \text { when: }\left(\frac{d^{2} N u}{d R e^{2}}\right)_{i: i+2} \geq-0.00015
$$

The notation $i: i+2$ indicates that at an arbitrary point $i$, the gradient was obtained using the three data points at $\operatorname{Re}(i), \operatorname{Re}(i+1)$ and $\operatorname{Re}(i+2)$ for increasing Reynolds numbers (while Eq. (17) used the results at the previous two Reynolds numbers).

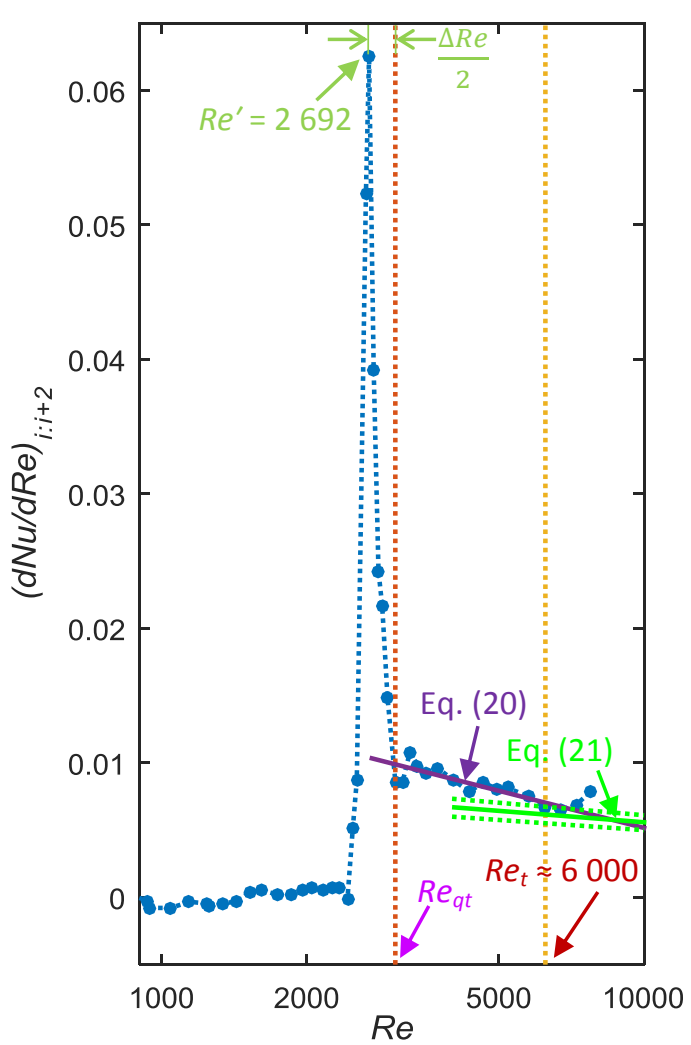

(a)

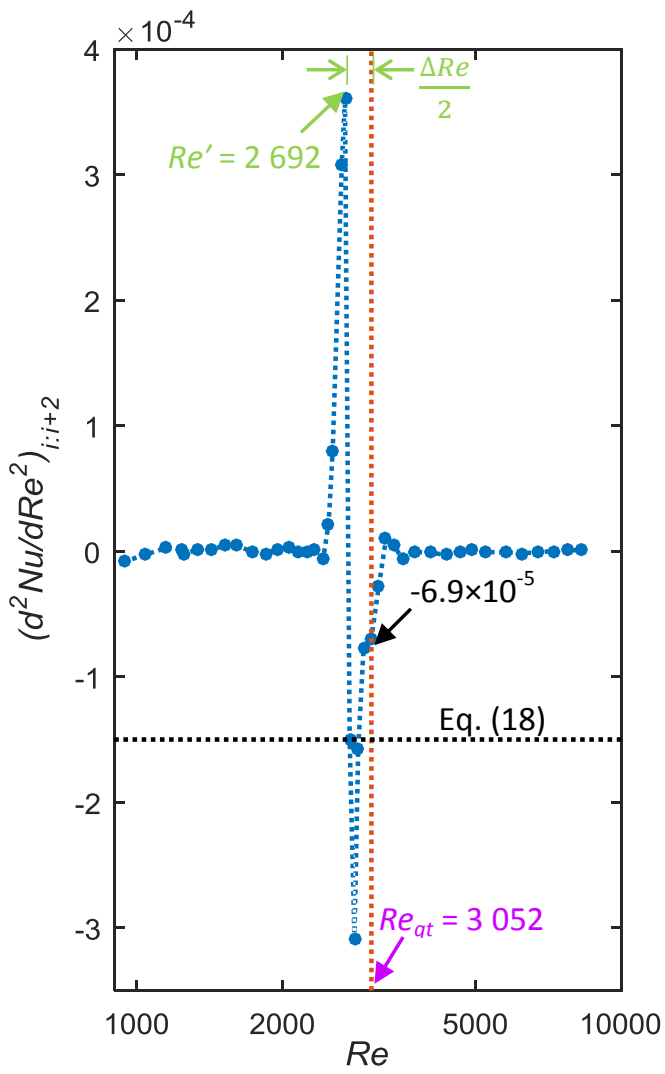

(b)

Fig. 5: (a) Nusselt number gradient and (b) gradient of Nusselt number gradients, as a function of Reynolds number at $x / D=98$ and a heat flux of $3 \mathrm{~kW} / \mathrm{m}^{2}$ in the $11.5 \mathrm{~mm}$ test section. 
Fig. 5(a) and (b) contains the Nusselt number gradients $(d N u / d R e)$, and gradient of the Nusselt number gradients $\left(d^{2} N u / d R e^{2}\right)$, respectively, as a function of Reynolds number at $x / D=98$ and heat flux of $3 \mathrm{~kW} / \mathrm{m}^{2}$ in the $11.5 \mathrm{~mm}$ test section. From Fig. 5(a) it follows that the start of the quasi-turbulent flow regime corresponds to the point where the trend of the gradient of $d N u / d R e$ changed. From Fig. 5(b) it follows that the quasi-turbulent flow regime started at 3052 , where the $d^{2} N u / d R e^{2}$ was approximately $-6.9 \times 10^{-5}$. Similar graphs were generated for all thermocouple stations and heat fluxes in both test sections, and it was found that the quasi-turbulent flow regime started when $d^{2} N u / d R e^{2}$ was greater than -0.00015 . We have found that this could be used as a satisfactory general criterion for almost all data.

\subsubsection{Start of the turbulent flow regime, $R e_{t}$}

The Reynolds number that corresponds to the start of the turbulent flow regime was the most challenging to obtain. The flow is considered as fully turbulent, once the Nusselt number- and Colburn $j$-factor lines fall on to, or become parallel, to the heat transfer coefficients predicted by fully turbulent correlations, for example the Colburn equation [45]. Although it follows from Fig. 5(a) that this Reynolds number corresponds to the point where the trend of the Nusselt number gradients changed (gradient decreased and became approximately constant), it was challenging to quantify it mathematically/computationally. It was found that the start of the turbulent flow regime (and end of the quasi-turbulent flow regime), $R e_{t}$, can be defined as the Reynolds number at the intersection of the trendlines through the Nusselt number gradients in the quasi-turbulent $\left((d N u / d R e)_{Q T}\right)$ and the turbulent $\left((d N u / d R e)_{T}\right)$ flow regimes:

$$
R e=R e_{t} \text { when: }\left(\frac{d N u}{d R e}\right)_{Q T}=\left(\frac{d N u}{d R e}\right)_{T}
$$

where

$$
\begin{aligned}
\left(\frac{d N u}{d R e}\right)_{Q T} & =0.7054 R e^{-0.534} \\
\left(\frac{d N u}{d R e}\right)_{T} & =0.0352 R e^{-0.2}
\end{aligned}
$$

Eq. (20) was obtained by doing a power curve fit through all the Nusselt number gradients in the quasi-turbulent flow regime $\left(R e_{c r}<R e<6000\right)$ of all the thermocouple stations in both test sections at the different heat fluxes, and is represented by the solid purple line in Fig. 5(a). Eq. (21) was obtained by taking the derivative of the Colburn equation [45] (which is 
valid for fully turbulent flow) with respect to Reynolds number, and is indicated by the solid green line in Fig. 5(a). Due to the relatively high uncertainties (due to the small temperature differences) in the turbulent flow regime, an uncertainty of $10 \%$ is indicated by the dotted green lines. From Fig. 5(a) it follows that the flow became fully turbulent at a Reynolds number of approximately 6000 , with an uncertainty of approximately $10 \%$. As a single trend line (Eq. (20)) was obtained through all the data in the quasi-turbulent flow regime, this value was true for all the results. However, this can be refined with experimental data (with low uncertainties, especially in the quasi-turbulent and turbulent flow regimes) by obtaining individual trendlines through the data in the quasi-turbulent flow regime.

\subsection{Flow characteristics}

\subsubsection{Laminar flow regime}

Meyer and Everts [31] found that the local laminar Nusselt numbers can be divided into three regions: Forced Convection Developing (FCD), Mixed Convection Developing (MCD) and Fully Developed (FD). The trend of the Nusselt numbers as a function of Reynolds number, is significantly affected by the characteristics of these three regions.

\subsubsection{Forced Convection Developing (FCD)}

When the flow is still developing, the local Nusselt numbers decrease along the tube length, as the thermal boundary layer develops (entrance effects). As the thermal boundary layer thickness is very thin in this region, free convection effects are negligible. The thermal entrance length increases with increasing Reynolds number, therefore at a fixed axial position, the thermal boundary layer thickness decreases, and the Nusselt numbers increase. The Nusselt numbers therefore increase with increasing Reynolds number and form a diagonal line with a positive gradient (line $L 1-L 1$ in Fig. 3):

$$
\frac{d N u}{d R e}>0
$$

\subsubsection{Mixed Convection Developing (MCD)}

In this region, the thermal boundary layer thickness is sufficient for free convection effects to be significant. As the flow is still developing, the thermal boundary layer thickness increases along the tube length. Free convection effects decrease the thermal entrance length [31], therefore at a fixed axial position, the thermal boundary layer thickness increases and the Nusselt number decreases (entrance effects). However, free convection effects increase 
with increasing thermal boundary layer thickness, which may lead to increasing Nusselt numbers along the tube length (free convection effects).

When the decrease in Nusselt number (due to the shorter thermal entrance length) is more than the increase due to free convection effects, entrance effects dominate and $(d N u / d R e)_{L}>0$ (Eq. (22)). However, when free convection effects dominate the entrance effects, the Nusselt numbers decrease with increasing Reynolds number, since the thermal boundary layer thickness and free convection effects decrease (line $L 2-L 2$ in Fig. 3):

$$
\frac{d N u}{d R e}<0
$$

\subsubsection{Fully Developed (FD)}

For fully developed forced convection flow, the Nusselt numbers form a horizontal line and should be equal to 4.36 :

$$
\frac{d N u}{d R e}=0
$$

When the flow is dominated by mixed convection, the Nusselt numbers are greater than 4.36. The Nusselt numbers decrease with increasing Reynolds number, since the free convection effects decrease, therefore $(d N u / d R e)_{L}<0$ (Eq. (23)).

\subsubsection{Transitional flow regime}

Previous work that has been done on flow in the transitional flow regime concluded that the transitional flow regime can be manipulated by changing the inlet geometry and heat flux, and that it varied when different locations on the test section were considered. To quantify these changes in the transitional flow regime, the width of the transitional flow regime, $\Delta R e$, as well as the transition gradient, $T G_{j}$, are defined.

\subsubsection{Width of the transitional flow regime}

The width of the transitional flow regime represents the Reynolds number range in which transition occurs:

$$
\Delta R e=R e_{q t}-R e_{c r}
$$




\subsubsection{Transition gradient}

The transition gradient (indicated by the dotted green $T G-T G$ line in Fig. 3(b)) represents the straight line between the Colburn $j$-factors at the start $\left(R e_{c r}\right)$ and end $\left(\operatorname{Re}_{q t}\right)$ of the transitional flow regime:

$$
T G_{j}=\frac{j_{q t}-j_{c r}}{R e_{q t}-R e_{c r}}
$$

This gives a good indication of how the heat transfer characteristics change in the transitional flow regime.

\subsubsection{Transitional flow inflection point, $R e^{\prime}$}

From Fig. 4 and Fig. 5(a) it follows that when $d N u / d R e$ was plotted as a function of Reynolds number, $d N u / d R e$ reached a prominent maximum at $R e^{\prime}$, which is in the middle of the transitional flow regime. Furthermore, when $d^{2} N u / d R e^{2}$ was plotted as a function of Reynolds number in Fig. 5(b), it follows that in the transitional flow regime, the gradient first increased with increasing Reynolds number up to a maximum, then it decreased (to negative gradients) to a minimum at the next Reynolds number increment, before it increased again. The inflection point in the transitional flow regime, is where $d^{2} N u / d R e^{2}$ changes from the maximum to the minimum. From Fig. 3 it follows that that both Nusselt numbers and Colburn $j$-factors increased in the transitional flow regime. However, as schematically indicated (and exaggerated) by the 's'-curve in Fig. 3, it follows from Fig. 5 that the increase in heat transfer coefficients with increasing Reynolds number, increased with increasing Reynolds number in the lower half of the transitional flow regime, and then decreased in the upper half as the flow approached the quasi-turbulent flow regime. The inflection point in the transitional flow regime is where the trend of the flow characteristics changes, and is in the middle of the transitional flow regime:

$$
R e^{\prime}=\frac{R e_{c r}+R e_{q t}}{2}=R e_{c r}+\frac{\Delta R e}{2}
$$

It was found that the inflection point predicted using Eq.(27), was within $4 \%$ of the middle the transitional flow regime (obtained using Eqs. (17) and (18)). Therefore, as $R e_{c r}$ and $R e^{\prime}$ are simpler to obtain than $R e_{q}$, Eq. (27) can also be used to obtain the start of the quasiturbulent flow regime. For this study, the physical mechanism of $R e^{\prime}$ was not investigated. 


\subsubsection{Quasi-turbulent flow regime}

Not much research has been devoted to the heat transfer and pressure drop characteristics in this flow regime, and it is often regarded as part of the transitional flow regime since the flow is not fully turbulent yet [28]. Although the heat transfer characteristics are closer to that of turbulent flow, an extension of the straight line (on a log-log scale) of the turbulent Nusselt numbers as a function of Reynolds number, overpredicts the Nusselt numbers in this regime [2], therefore $(d N u / d R e)_{Q T}>(d N u / d R e)_{T}$. From Fig. 5(a) it follows that $d N u / d R e$ decreased from 0.0098 to 0.0066 , as the Reynolds number increased and the flow approached fully turbulent flow. The Nusselt numbers in the quasi-turbulent flow regime increase with increasing Reynolds number and form a diagonal line (Fig. 3(a)). However, the Colburn $j$ factors in this regime increase and then decrease slightly with increasing Reynolds number, forming a concave curve as the flow regime changes from transitional to fully turbulent (Fig. $3(b))$.

\subsubsection{Turbulent flow regime}

The Colburn $j$-factor is proportional to Nusselt number, but inversely to Reynolds number. Therefore, although the turbulent Nusselt numbers increase with increasing Reynolds number, the increase in Nusselt number is less than the increase in Reynolds number, which leads to decreasing Colburn $j$-factors in the turbulent flow regime.

\section{Results and discussion}

\subsection{Influence of axial position}

To investigate the influence of axial position on the heat transfer characteristics in the transitional flow regime, the Nusselt numbers and Colburn $j$-factors at a heat flux of $1 \mathrm{~kW} / \mathrm{m}^{2}$ in the $4 \mathrm{~mm}$ test section are compared as a function of Reynolds number, for different axial positions in Fig. 6. To avoid any influences of free convection effects, a low heat flux was chosen to ensure that the flow was dominated by forced convection conditions. Although experiments in general were conducted up to a Reynolds number of 10 000, the Reynolds number was not increased above 6000 for the forced convection experiments, since the uncertainty of the heat transfer coefficients became too large due to the small temperature differences inside the test section. However, the transitional flow regime, as well as sufficient parts of the laminar and quasi-turbulent flow regimes, were covered. 


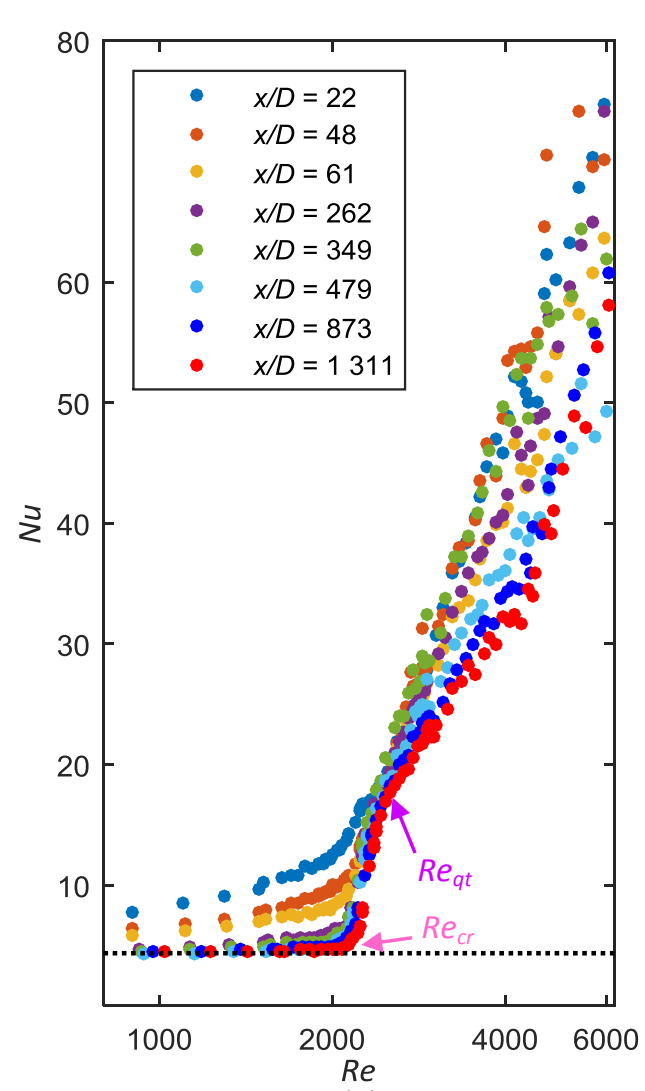

(a)

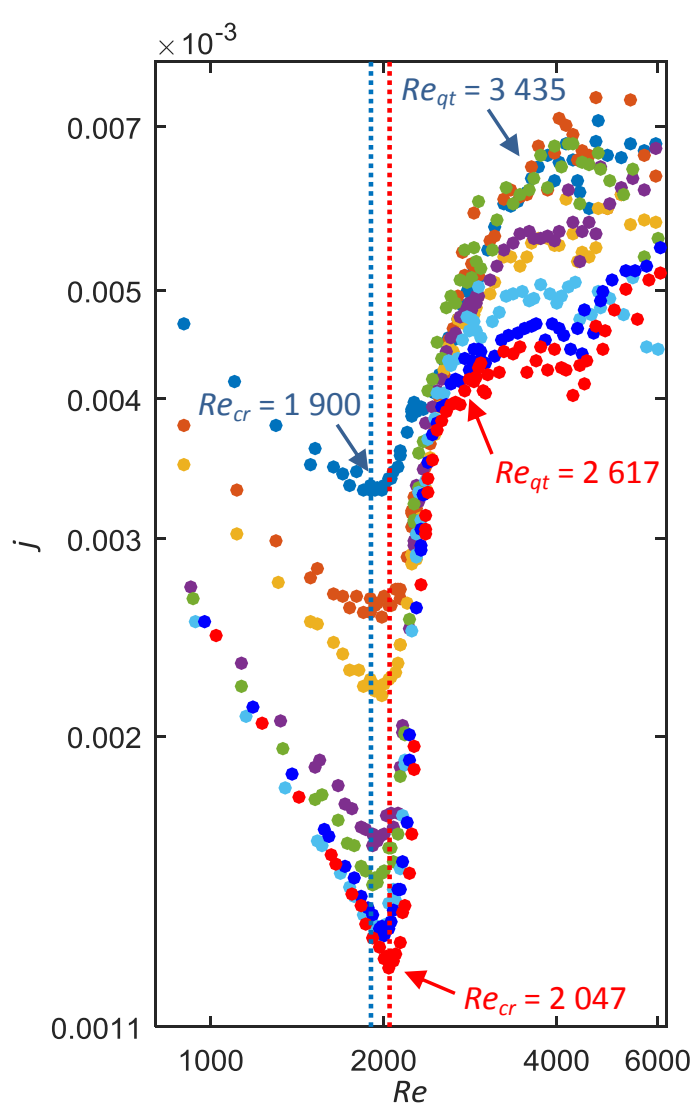

(b)

Fig. 6: Comparison of (a) Nusselt numbers and (b) Colburn j-factors as a function of Reynolds number at a heat flux of $1 \mathrm{~kW} / \mathrm{m}^{2}$ in the $4 \mathrm{~mm}$ test section. The start of the transitional flow regime at $x / D=22$ and $x / D=1311$ are indicated by the vertical dotted lines.

Between Reynolds numbers of 900 and approximately 2000 (depending on the tube location), the flow was laminar $\left((d j / d R e)_{L}<0\right)$. The theoretical fully developed forced convection Nusselt number of 4.36 is indicated by the black dotted line. From Fig. 6(a) it follows that, at a fixed Reynolds number, the laminar Nusselt numbers were a maximum near the inlet of the test section $(x / D=22)$, and then decreased to approximately 4.36 , as the flow developed along the tube length. For $x / D \geq 479$, the laminar Nusselt numbers were in very good agreement (average deviation of $6.4 \%$ ) with the theoretical Nusselt number of 4.36, which confirmed that fully developed forced convection conditions were successfully obtained. As free convection effects were negligible and the flow was still developing for $x / D<479$, entrance effects dominated and $(d N u / d R e)_{L}>0$ (Eq. (22)). However, the gradient of the laminar Nusselt numbers, $(d N u / d R e)_{L}$, decreased and approached zero as $x / D$ increased and the flow approached fully developed flow (Eq. (24)).

As indicated by the vertical dotted lines in Fig. 6(b), the transitional flow regime started $\left(R e_{c r}\right)$ at a Reynolds number of 1900 at $x / D=22$, and at a Reynolds number of 2047 at $x / D=1311$. However, Everts and Meyer [30] found that transition started at the same 
moment in time along the entire test section. As the temperature gradient across the test section was zero during their isothermal experiments, the critical Reynolds number of the different tube lengths (developing and fully developed flow) was the same. The increasing Reynolds numbers in Fig. 6(b) were only due to the temperature gradient along the tube length, and the decreasing viscosity with increasing temperature (this will be investigated in Fig. 8).

The end of the transitional flow regime $\left(R e_{q t}\right)$ became more pronounced as the flow developed along the tube length. From the Colburn $j$-factors in Fig. 6(b) it follows that the Reynolds number at which transition ended $\left(R e_{q t}\right)$, decreased from 3435 at $x / D=22$, to 2617 at $x / D=1311$. This caused the width of the transitional flow regime $(\Delta R e)$ to decrease from a Reynolds number range of 1535 to 570 . As $\Delta R e$ decreased, the transition gradient $\left(T G_{j}\right.$ in Fig. 3) increased along the tube length. Meyer and Everts [31] found that as the Reynolds number in the transitional flow regime was increased, the transition region inside the test section decreased and a larger portion of the test section contained flow in the quasi-turbulent and turbulent regions. This implies that at two fixed axial positions, for example $x / D=48$ and $x / D=1311, x / D=48$ experienced transition for a wider range of Reynolds numbers, which explains why $\Delta R e$ decreased along the tube length. As there was no significant difference in the transition gradient for $x / D>479$ in Fig. 6(b), it follows that $\Delta R e$ became constant once the flow was fully developed.

As expected, the heat transfer coefficients in the quasi-turbulent flow regime did not change significantly along the tube length, since the flow was almost fully turbulent (and thus fully developed). The scatter in the Nusselt numbers and Colburn $j$-factors was due to the small temperature differences, and thus increased uncertainties, in this regime. If one thermocouple station measured a slightly higher (or lower) temperature (although it was still within the uncertainty of the thermocouple), the Nusselt numbers and Colburn $j$-factors were also higher (or lower) compared to the rest.

\subsection{Influence of free convection}

To investigate the influence of free convection, the Nusselt numbers and Colburn $j$-factors are compared at heat fluxes of $3 \mathrm{~kW} / \mathrm{m}^{2}$ (Fig. 7(a) and (b)) and $8 \mathrm{~kW} / \mathrm{m}^{2}$ (Fig. 7(c) and (d)) in the $4 \mathrm{~mm}$ test section, and at a heat flux of $3 \mathrm{~kW} / \mathrm{m}^{2}$ in the $11.5 \mathrm{~mm}$ test section (Fig. 7(e) and (f)). Although the bulk Reynolds number in the $4 \mathrm{~mm}$ test section was not decreased below 1800 at a heat flux of $8 \mathrm{~kW} / \mathrm{m}^{2}$ (the outlet temperature exceeded $70^{\circ} \mathrm{C}$ ), a sufficient part of the laminar flow regime was still covered. Furthermore, the Reynolds number in the $4 \mathrm{~mm}$ 


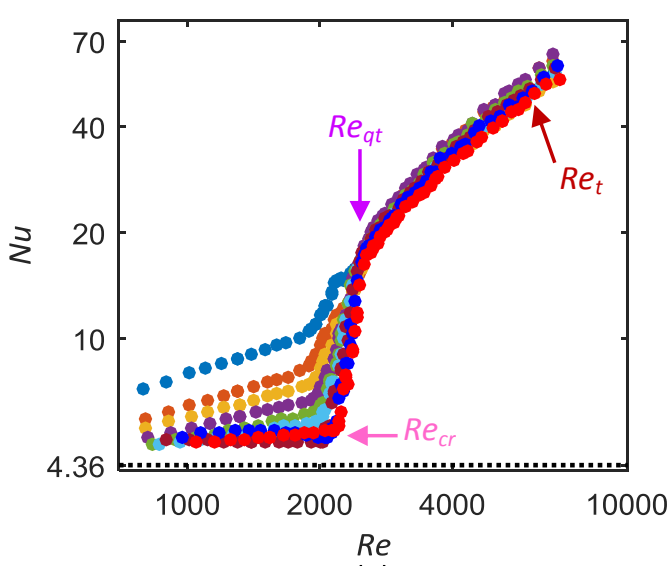

(a)

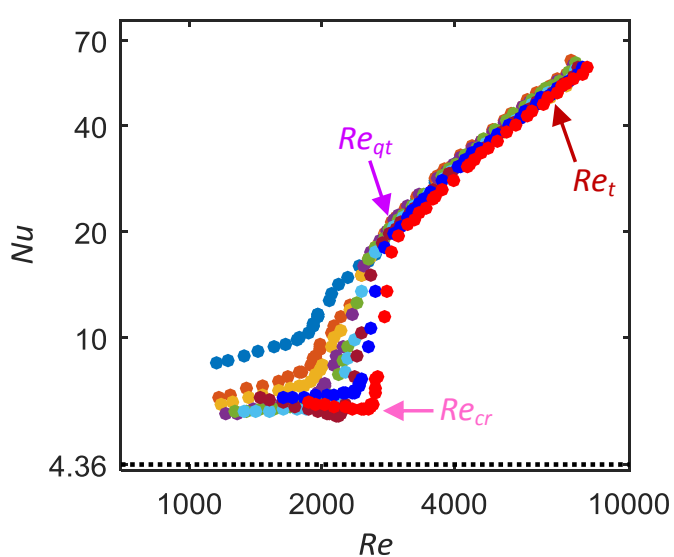

(c)

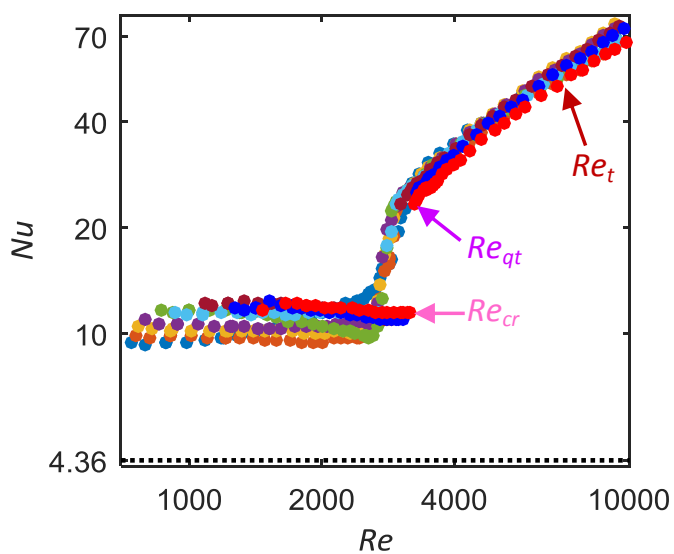

(e)

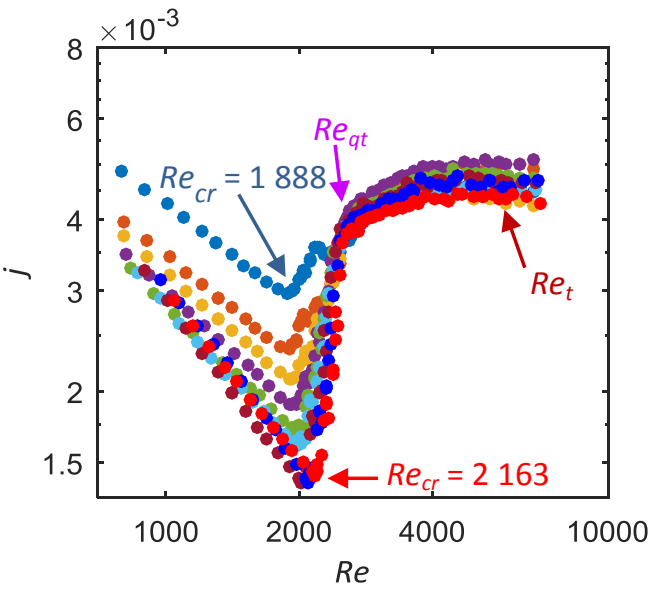

(b)

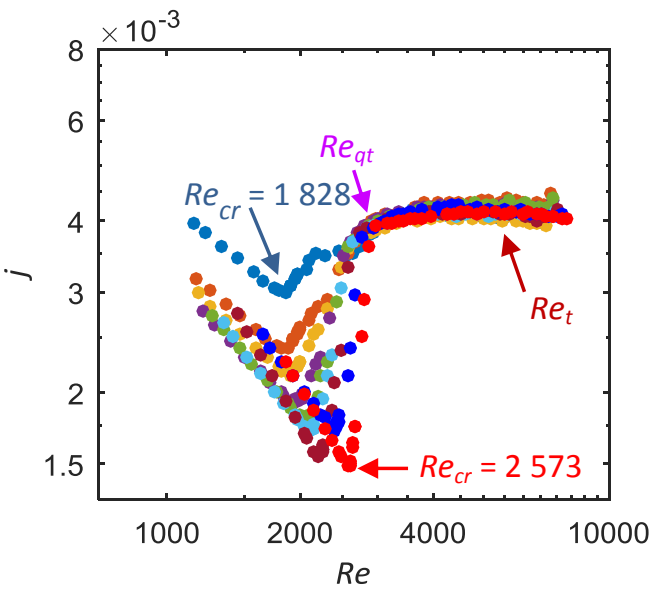

(d)

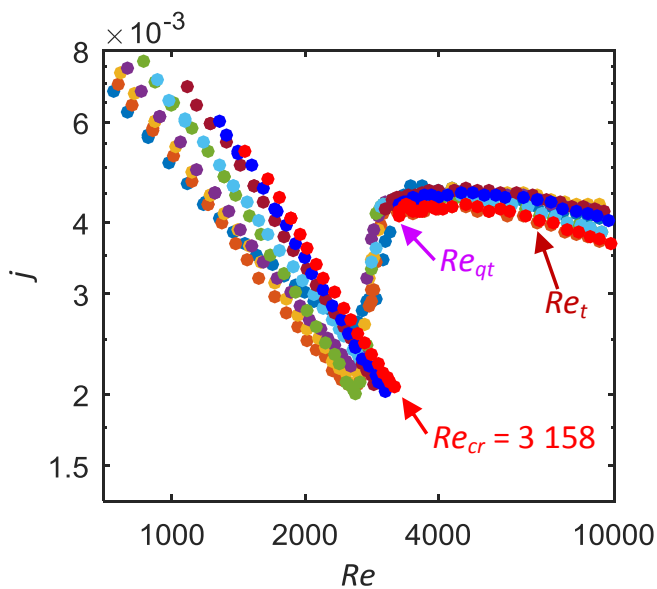

(f)

$$
\begin{aligned}
& -x / D=22[4 \mathrm{~mm}], x / D=24[11.5 \mathrm{~mm}] \\
& x / D=48[4 \mathrm{~mm}], x / D=50[11.5 \mathrm{~mm}] \\
& -x / D=61[4 \mathrm{~mm}], x / D=63[11.5 \mathrm{~mm}] \\
& -x / D=96[4 \mathrm{~mm}], x / D=98[11.5 \mathrm{~mm}] \\
& -x / D=175[4 \mathrm{~mm}], x / D=177[11.5 \mathrm{~mm}] \\
& -x / D=262[4 \mathrm{~mm}], x / D=264[11.5 \mathrm{~mm}] \\
& -x / D=392[4 \mathrm{~mm}], x / D=393[11.5 \mathrm{~mm}] \\
& -x / D=623[4 \mathrm{~mm}], x / D=654[11.5 \mathrm{~mm}] \\
& \quad x / D=873[4 \mathrm{~mm}], x / D=802[11.5 \mathrm{~mm}]
\end{aligned}
$$

Fig. 7: Comparison of (a) Nusselt numbers and (b) Colburn j-factors at a heat flux of $3 \mathrm{~kW} / \mathrm{m}^{2}$ and (c) Nusselt numbers and (d) Colburn j-factors at a heat flux of $8 \mathrm{~kW} / \mathrm{m}^{2}$ in the $4 \mathrm{~mm}$ test section, and (e) Nusselt numbers and (f) Colburn $j$ factors at a heat flux of $3 \mathrm{~kW} / \mathrm{m}^{2}$ in the $11.5 \mathrm{~mm}$ test section, as a function of Reynolds number. 
test section was not increased above 8000 , since the temperature differences became too small and the uncertainties too high to obtain accurate and reliable results. The results are discussed in the following order: laminar flow (Section 0), quasi-turbulent and turbulent flow (Section 6.2.2), and transitional flow (Section 6.2.3).

\subsubsection{Laminar flow}

From Fig. 7(a) it follows that, as expected, free convection effects caused the laminar Nusselt numbers to increase above 4.36, and increased further with increasing heat flux (Fig. 7(c)) and tube diameter (Fig. 7(e)). When comparing the laminar Colburn $j$-factors of the two heat fluxes in the $4 \mathrm{~mm}$ test section (Fig. 7(b) and (d)), it follows that between $x / D=22$ and $x / D=61$, there was no significant difference in the trend and magnitude of the Colburn $j$ factors. The heat transfer coefficients fell into the FCD region for $22 \leq x / D \leq 262$ and $22 \leq x / D \leq 61$, at heat fluxes of $3 \mathrm{~kW} / \mathrm{m}^{2}$ and $8 \mathrm{~kW} / \mathrm{m}^{2}$, respectively. Therefore, it was not affected by heat flux, and $d N u / d R e>0$ since entrance effects dominated (Eq. (22)).

For $x / D>262$ and $x / D>96$ at heat fluxes of $3 \mathrm{~kW} / \mathrm{m}^{2}$ and $8 \mathrm{~kW} / \mathrm{m}^{2}$, respectively, in the $4 \mathrm{~mm}$ test section, and for $x / D>24$ in the $11.5 \mathrm{~mm}$ test section, the flow was in the MCD region. As the thermal entrance length decreased with increasing Grashof number, thus tube diameter and heat flux, the thermal boundary layer developed faster and the heat transfer coefficients fell into the MCD region at smaller values of $x / D$ [31]. In this region, free convection effects increased along the tube length, as well as with increasing heat flux and tube diameter, which caused $(d N u / d R e)_{L}$ and $(d j / d R e)_{L}$ to decrease. From Fig. 7(e) it follows that the difference between the laminar Colburn $j$-factors of the different thermocouple stations was a maximum at a Reynolds number of 800 , but became negligible as the Reynolds number was increased to 2500 . This is due to the decreasing thermal boundary layer thickness with increasing Reynolds number, which led to decreased free convection effects and thus $d N u / d R e<0$.

\subsubsection{Quasi-turbulent and turbulent flow}

As will be discussed in Section 6.2.3, transition was delayed with increasing heat flux and tube diameter, while there was no significant difference in the start of the turbulent flow regime. The flow became fully turbulent at a Reynolds number of approximately 6000 , therefore the width of the quasi-turbulent flow regime decreased with increasing free convection effects. As expected, there was no significant difference between the turbulent heat transfer coefficients of the different heat fluxes and tube diameters, since free convection effects were suppressed by the velocity of the fluid. The scatter in heat transfer coefficients 
in these flow regimes decreased with increasing heat flux and tube diameter, due to the increased temperatures that led to decreased uncertainties.

\subsubsection{Transitional flow}

From Fig. 7(b) and (d), it follows that free convection effects (due to the increased heat flux) caused transition to occur earlier between $x / D=22$ and $x / D=61\left(R e_{c r}=1888\right.$ and $R e_{c r}=1828$ at $x / D=22$ for heat fluxes of $3 \mathrm{~kW} / \mathrm{m}^{2}$ and $8 \mathrm{~kW} / \mathrm{m}^{2}$, respectively) while it was delayed as $x / D$ was increased further $\left(R e_{c r}=2163\right.$ and $R e_{c r}=2573$ at $x / D=873$ for heat fluxes of $3 \mathrm{~kW} / \mathrm{m}^{2}$ and $8 \mathrm{~kW} / \mathrm{m}^{2}$, respectively). To investigate this, Fig. 8 compares the surface temperatures and local Reynolds numbers as a function of axial position at the bulk critical Reynolds number at heat fluxes of $1 \mathrm{~kW} / \mathrm{m}^{2}$ (forced convection), $3 \mathrm{~kW} / \mathrm{m}^{2}$ and $8 \mathrm{~kW} / \mathrm{m}^{2}$ in the $4 \mathrm{~mm}$ test section.

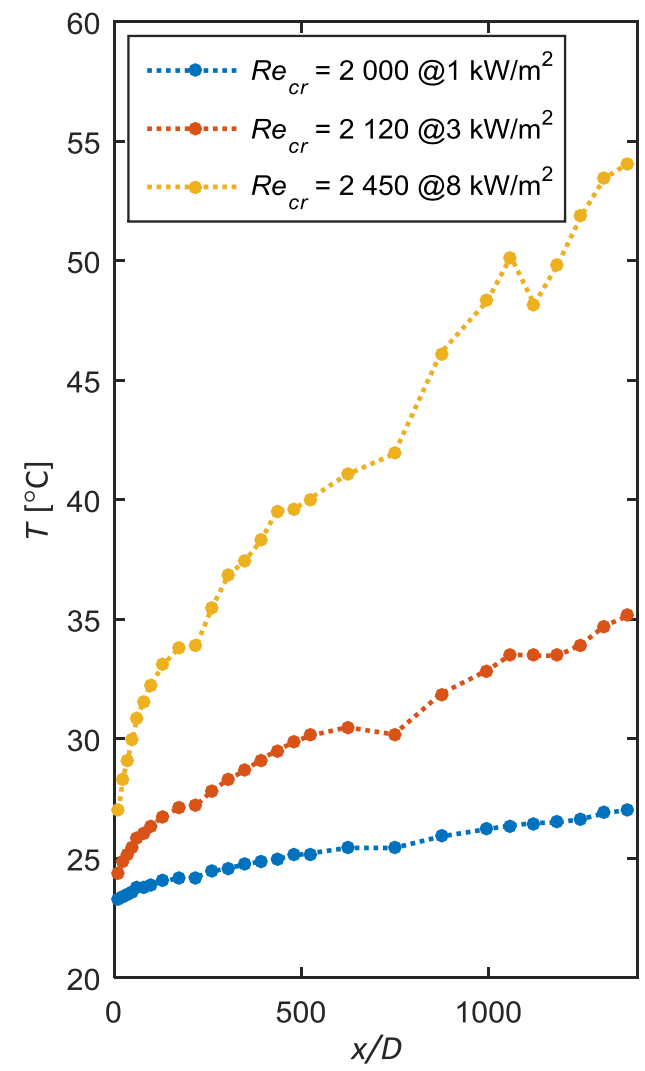

(a)

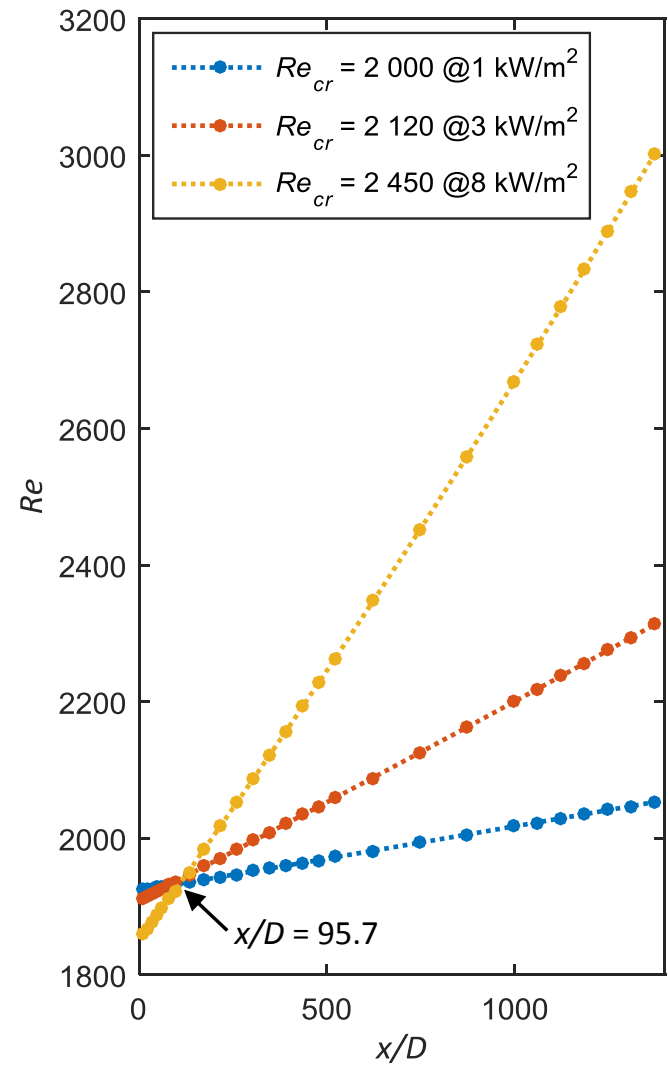

(b)

Fig. 8: Comparison of (a) surface temperatures and (b) local Reynolds numbers as a function of axial position at the critical Reynolds number at heat fluxes of $1 \mathrm{~kW} / \mathrm{m}^{2}$ (forced convection), $3 \mathrm{~kW} / \mathrm{m}^{2}$ and $8 \mathrm{~kW} / \mathrm{m}^{2}$ in the $4 \mathrm{~mm}$ test section.

From Fig. 8(a) it follows that the temperature gradient along the test section increased significantly with increased heat flux. As the Reynolds number is inversely proportional to viscosity (that decreased with increasing temperature), the critical Reynolds numbers in Fig. 
8(b) increased along the tube length, although transition started at the same moment in time (same bulk critical Reynolds number) along the entire test section. From Fig. 8(b) it follows that for $x / D$ less than 95.7, the critical Reynolds numbers decreased with increasing heat flux, since transition occurred earlier (at lower mass flow rates), however, as $x / D$ was increased further, the critical Reynolds numbers increased due to the increased temperature gradients along the test section.

Fig. 9 contains the standard deviation of the mass flow rate measurements as a function of mass flow rate at heat fluxes of $1 \mathrm{~kW} / \mathrm{m}^{2}$ (forced convection), $3 \mathrm{~kW} / \mathrm{m}^{2}$ and $8 \mathrm{~kW} / \mathrm{m}^{2}$ in the $4 \mathrm{~mm}$ test section. The start of transition corresponds to the point where mass flow rate fluctuations occurred, therefore the standard deviation of the mass flow rate measurements began to increase. From this figure it follows that at a heat flux of $1 \mathrm{~kW} / \mathrm{m}^{2}$, transition occurred at a mass flow rate of $0.00566 \mathrm{~kg} / \mathrm{s}$, while it occurred at $0.00561 \mathrm{~kg} / \mathrm{s}$ and $0.00544 \mathrm{~kg} / \mathrm{s}$ when the heat flux was increased to $3 \mathrm{~kW} / \mathrm{m}^{2}$ and $8 \mathrm{~kW} / \mathrm{m}^{2}$, respectively. This confirms that free convection effects caused transition to occur earlier (with reference to mass flow rate), as is evident from Fig. 8(b) for $x / D<95.7$.

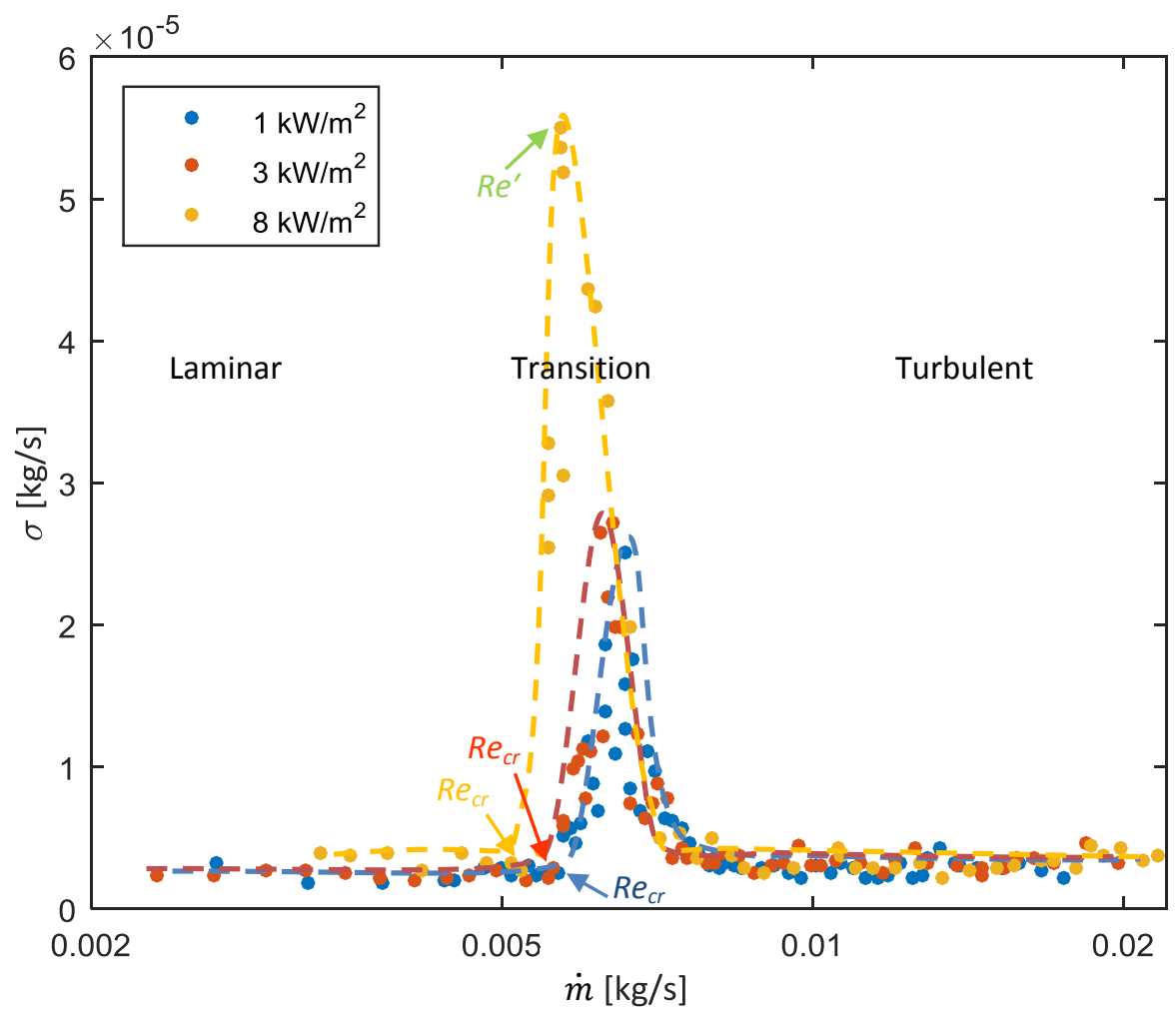

Fig. 9: Standard deviation of the mass flow rate measurements as a function of mass flow rate at heat fluxes of $1 \mathrm{~kW} / \mathrm{m}^{2}$ (forced convection), $3 \mathrm{~kW} / \mathrm{m}^{2}$ and $8 \mathrm{~kW} / \mathrm{m}^{2}$ in the $4 \mathrm{~mm}$ test section.

Fig. 10 compares the standard deviations of the temperature measurements at the top of the $4 \mathrm{~mm}$ test section, as a function of axial position for laminar, transitional, quasi-turbulent 
and turbulent Reynolds numbers at a heat flux of $8 \mathrm{~kW} / \mathrm{m}^{2}$. As expected, the standard deviations were a minimum in the laminar flow regime $\left(R e<R e_{c r}\right)$. Once transition started $\left(R e>R e_{c r}\right)$, the standard deviation increased along the entire test section, indicating that fluctuations occurred, and similar to the findings of Everts and Meyer [30], transition started at the same moment in time along the entire test section. Furthermore, the standard deviation also increased along the test section from $0.05^{\circ} \mathrm{C}$ at $x / D=48$ to $0.27^{\circ} \mathrm{C}$ at $x / D=1373$, due to the development of the thermal boundary layer that led to increased free convection effects [31]. Similar to the mass flow rate fluctuations in Fig. 9, the temperature fluctuations in the transitional flow regime increased with increasing Reynolds number $\left(R e>R e_{c r}\right.$ and $\left.R e \gg R e_{c r}\right)$. At $R e=R e_{q t}$, fluctuations were significant for $x / D<600$, but were negligible for $x / D>600$. Thus, the first part of the test section contained flow in the transitional flow regime, while the last part of the test section contained flow in the quasi-turbulent flow regime. It can therefore be concluded that although the start of transition was independent of axial position (occurred at the same moment in time), the end of transition was not.

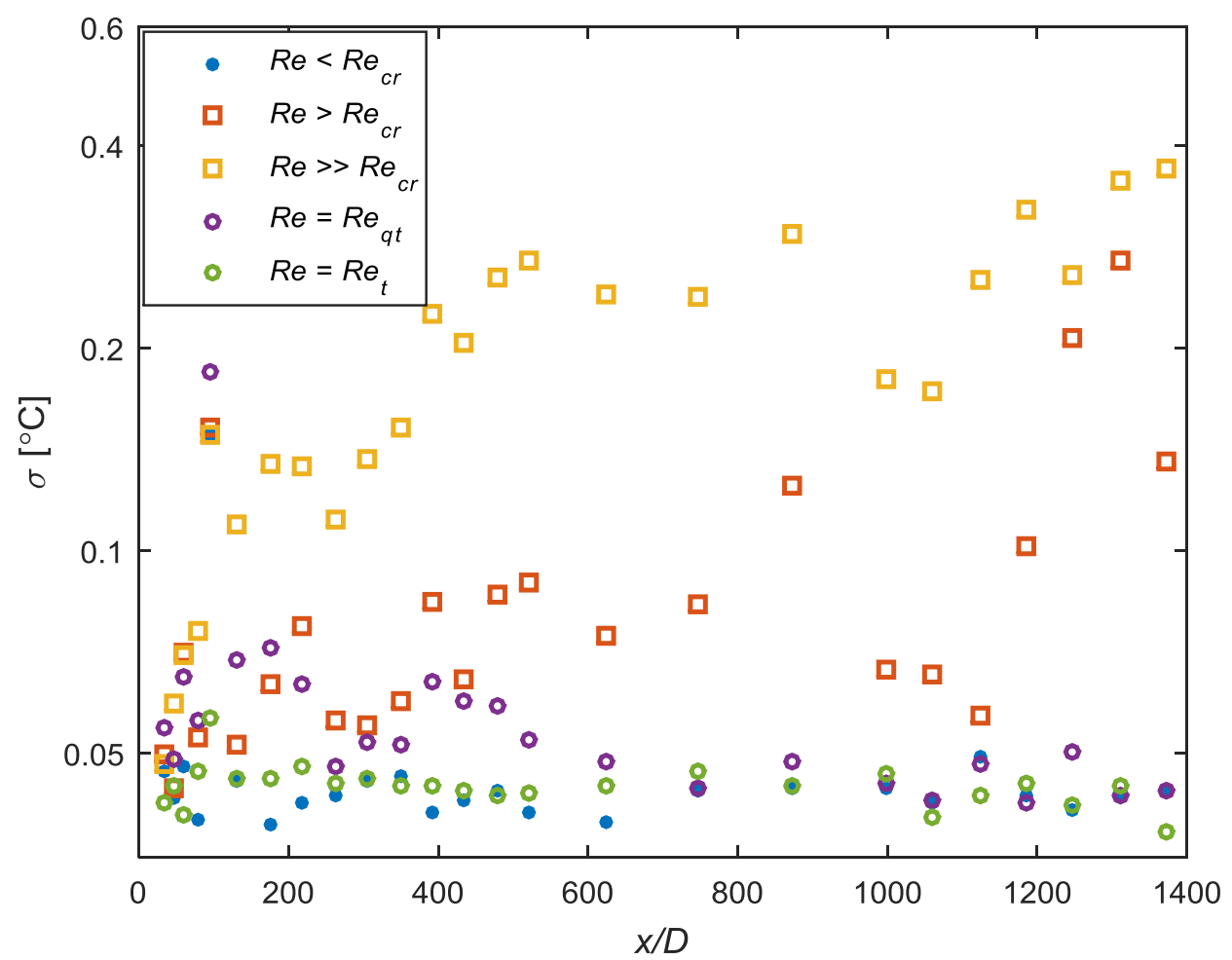

Fig. 10: Standard deviation of surface temperatures at the top of the $4 \mathrm{~mm}$ test section as a function of axial position at different Reynolds numbers and a heat flux of $8 \mathrm{~kW} / \mathrm{m}^{2}$.

The Reynolds numbers at which the transitional flow regime started $\left(R e_{c r}\right)$ and ended $\left(R e_{q t}\right)$ for the results in Fig. 7, as well as additional heat fluxes, are summarised in Fig. 11(a), while Fig. 11(b) compares the width of the transition flow regime $(\Delta R e)$. In Fig. 11(a), the 
empty markers represent the start of the transitional flow regime, while the filled markers represent the end of the transitional flow regime. Although transition occurred at the same moment in time along the entire test section (Fig. 10) and earlier with increasing free convection effects (Fig. 9), it follows from Fig. 11(a) that the critical Reynolds numbers increased along the tube length, and the gradient of the critical Reynolds numbers increased with increasing heat flux and tube diameter.

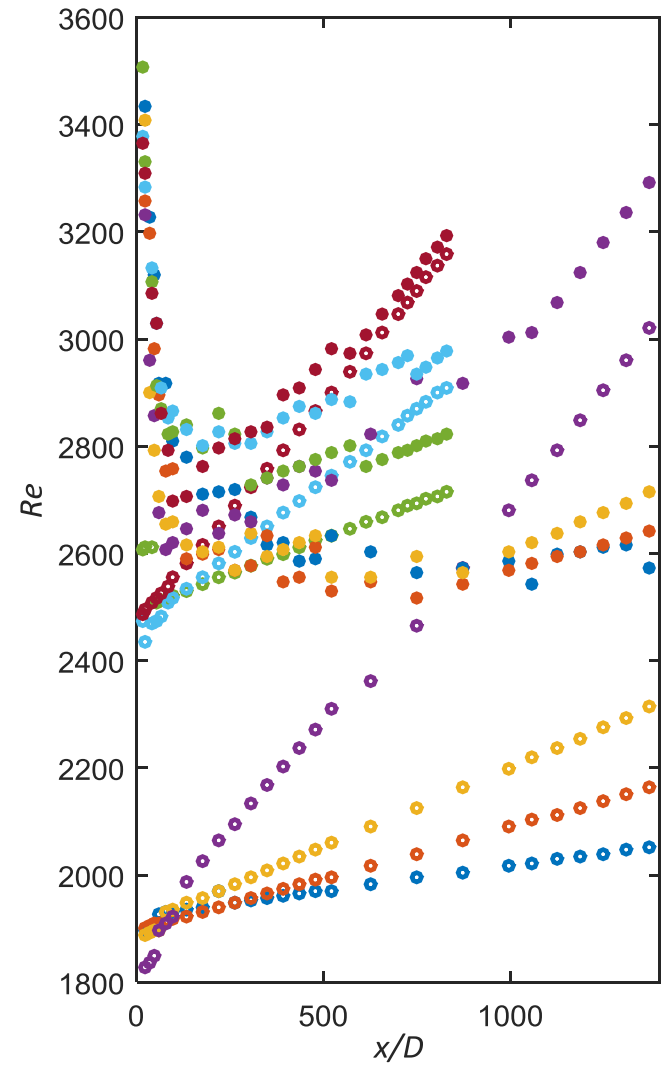

(a)

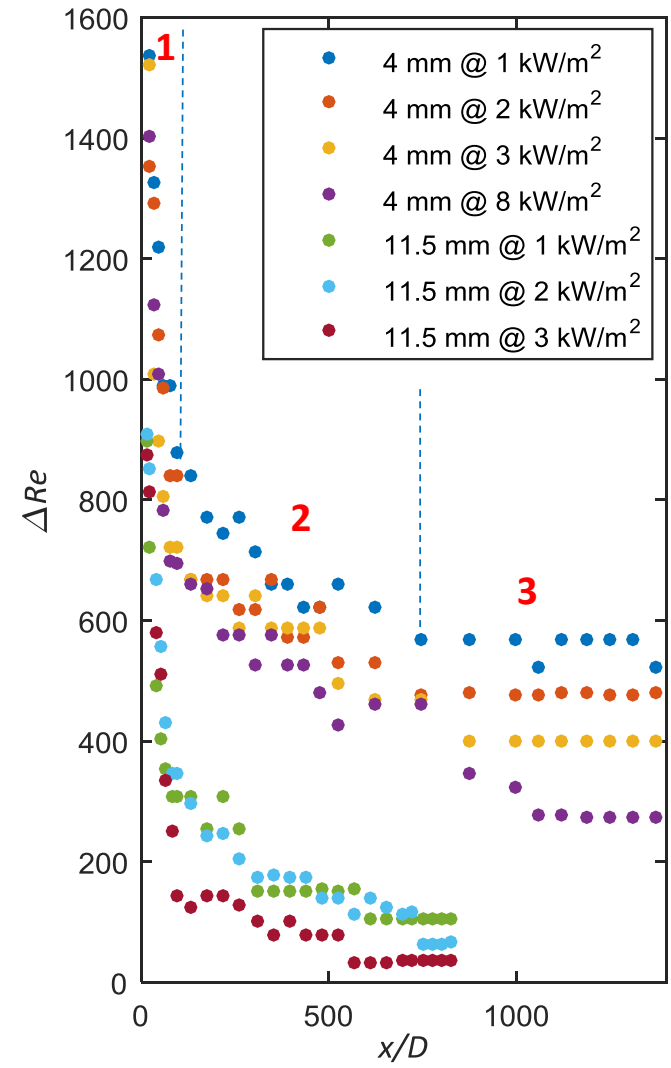

(b)

Fig. 11: Comparison of (a) Reynolds numbers at which transition started and ended and (b) width of the transitional flow regime as a function of axial position for different heat fluxes in the $4 \mathrm{~mm}$ and $11.5 \mathrm{~mm}$ test sections. In Fig. 11(a), the empty markers represent the start of transition, while the filled markers represent the end of transition.

Furthermore, near the inlet of the test section, the Reynolds number at which transition ended decreased significantly with increasing axial position, but increased as $x / D$ was increased further. From Fig. 11(b) it follows that $\Delta R e$ decreased along the tube length when the flow was developing, and became approximately constant once the flow was fully developed. Since transition started at the same moment in time along the entire test section and $\Delta R e$ decreased along the test section (Fig. 11(b)), it can be concluded that $R e_{q t}$ occurred earlier as the flow developed along the test section, but at the same moment in time once the flow was fully developed. This is as expected since the transition region inside the test section decreased [31] with increasing Reynolds number (fluid velocity) and/or Grashof 
number (free convection effects). Therefore, at a fixed Reynolds number, part of the test section might be in the transition region, while the remaining part of the test section might already be in the quasi-turbulent or even turbulent region.

From Fig. 7 and Fig. 11(a) it follows that transition occurred significantly earlier in the $4 \mathrm{~mm}$ test section $\left(R e_{c r} \approx 1900\right)$ than in the $11.5 \mathrm{~mm}$ test section $\left(R e_{c r} \approx 2500\right)$. There are two possible reasons for this: (1) Reynolds number is proportional to tube diameter and therefore increased with increasing tube diameter. (2) A greater contraction ratio (ratio of the flow-calming section diameter to the test section diameter) to the $4 \mathrm{~mm}$ test section caused a different disturbance of the boundary layer at the inlet of the test section, which caused transition to occur earlier. The contraction ratio in the $4 \mathrm{~mm}$ test section was 60.5 , while it was 14.9 in the $11.5 \mathrm{~mm}$ test section, and approximately 10 in the work of Ghajar and coworkers $[3-8,11,46]$.

From Fig. 11(b) it follows that when the flow was fully developed in the $4 \mathrm{~mm}$ test section, $\Delta R e$ was 580 at a heat flux of $1 \mathrm{~kW} / \mathrm{m}^{2}$, but decreased to 270 when the heat flux was increased to $8 \mathrm{~kW} / \mathrm{m}^{2}$. As free convection effects were increased further by increasing the tube diameter, $\Delta R e$ decreased from approximately 100 at a heat flux of $1 \mathrm{~kW} / \mathrm{m}^{2}$, to 35 at a heat flux of $3 \mathrm{~kW} / \mathrm{m}^{2}$. At this heat flux, severe fluctuations occurred inside the test section and the flow regime continuously alternated between the laminar and quasi-turbulent flow regimes. After time (up to 1 hour) the flow stabilised at the critical Reynolds number, and then in the quasi-turbulent flow regime at the next increasing experimental Reynolds number increment. Therefore, the transitional flow regime became negligible and $\Delta R e$ of 35 , was the smallest possible pump increment. This confirms that free convection effects caused the transition region (in terms of axial position) to decrease and become negligible at the end of the test section (where the flow was fully developed). This in turn caused the transitional flow regime (in terms of Reynolds number) to become negligible when the flow was fully developed, as was found in Fig. 7(e) and (f).

From Fig. 11(b) it also follows that when free convection effects were negligible $\left(1 \mathrm{~kW} / \mathrm{m}^{2}\right.$ in the $4 \mathrm{~mm}$ test section), $\Delta R e$ gradually decreased and became constant at a Reynolds number range of 570 at $x / D=748$. As the heat flux (and thus free convection effects) was increased, the axial position at which $\Delta R e$ became constant increased, while the opposite trend was observed in the $11.5 \mathrm{~mm}$ test section. For the $4 \mathrm{~mm}$ test section, the average Grashof number in the transitional flow regime was approximately 100 at a heat flux of $1 \mathrm{~kW} / \mathrm{m}^{2}$, and increased to 500 and 2000 as the heat flux was increased to $3 \mathrm{~kW} / \mathrm{m}^{2}$ and $8 \mathrm{~kW} / \mathrm{m}^{2}$, respectively. In the $11.5 \mathrm{~mm}$ test section, the average transitional Grashof number 
at heat fluxes of $1 \mathrm{~kW} / \mathrm{m}^{2}$ and $3 \mathrm{~kW} / \mathrm{m}^{2}$, was approximately 7000 and 15000 , which is an order of magnitude more than in the $4 \mathrm{~mm}$ test section. Meyer and Everts [31] found that once free convection effects become significant, the fluctuations inside the test section were disturbed and transition to occurred slower compared to forced convection conditions. However, as the Grashof number was increased further, the fluctuations were enhanced and caused transition to occur faster.

Overall it can be concluded from Fig. 11(b) that the transitional flow regime of developing and fully developed flow, can be divided into three regions in terms of axial position. As these regions were affected by free convection effects, it was only indicated for the forced convection case $\left(1 \mathrm{~kW} / \mathrm{m}^{2}\right.$ in the $4 \mathrm{~mm}$ test section). In region $1, \Delta R e$ decreased significantly along the tube length as the thermal boundary layer thickness increased. Due to the small thermal boundary layer thickness, free convection effects had a negligible influence on $\Delta R e$. In region 2, the thermal boundary layer thickness was sufficient for free convection effects to become significant. Therefore, $\Delta R e$ decreased with axial position (due to the increasing thermal boundary layer thickness) as well as with increasing heat flux and tube diameter, since free convection effects caused the flow to transition faster from laminar to turbulent. Once the flow was fully developed (region 3), $\Delta R e$ was independent of axial position. However, it decreased significantly with increasing heat flux and tube diameter, and even became negligible when the Grashof number was very high $\left(3 \mathrm{~kW} / \mathrm{m}^{2}\right.$ in the $11.5 \mathrm{~mm}$ test section).

Similar to Fig. 6(b), the transition gradients in Fig. 7(b), (d) and (f) increased along the test section as the flow approached fully developed flow, as well as with increased free convection effects due to increased heat fluxes and tube diameter. Fig. 12 compares the transition gradient, $T G_{j}$, as a function of axial position for different heat fluxes in the $4 \mathrm{~mm}$ and $11.5 \mathrm{~mm}$ test sections. An overall trend in this graph is that the transition gradient increased along the tube length, as the flow approached fully developed flow and free convection effects increased. This is as expected since the laminar-turbulent transition along the tube length occurred faster [31], causing $\Delta R e$ to decrease.

However, from close inspection it follows that when $x / D$ was less than 479 , the transition gradient in the $4 \mathrm{~mm}$ test section decreased with increasing heat flux. It was concluded from Fig. 7 that, near the inlet of the test section $(x / D<96)$, the critical Reynolds number decreased with increasing heat flux, but the magnitude of the Colburn $j$-factor at the critical Reynolds number increased. This caused the transition gradient to increase slightly (take note that a $\log$ scale was used for the $y$-axis in Fig. 12 to better illustrate the detail in the 
$4 \mathrm{~mm}$ test section). Between $x / D=96$ and $x / D=479$ in the $4 \mathrm{~mm}$ test section, both the critical Reynolds number and the magnitude of the Colburn $j$-factors at the critical Reynolds number increased with increasing heat flux, which led to a decreased transition gradient. When $x / D$ was greater than 479 , the increase in critical Reynolds number with increasing heat flux (due to the increased temperature gradient), was sufficient for the transition gradient to increase, although the magnitude of the Colburn $j$-factor at the critical Reynolds number increased.

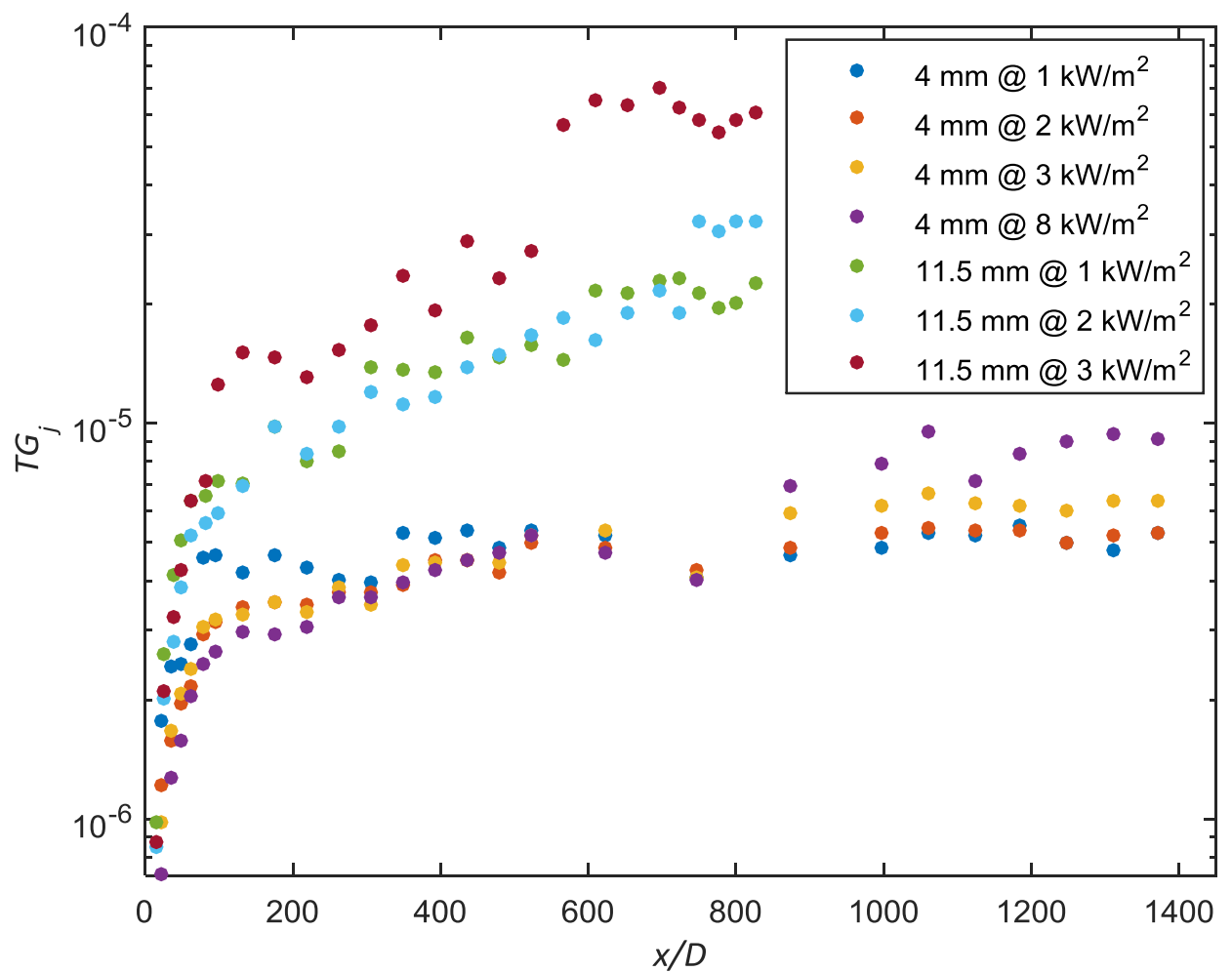

Fig. 12: Comparison of the transition gradients as a function of axial position for different heat fluxes in the $4 \mathrm{~mm}$ and $11.5 \mathrm{~mm}$ test sections.

Once the flow was fully developed, the transition gradient became approximately constant along the tube length (since $\Delta R e$ remained constant), but increased with increasing free convection effects (since $\Delta R e$ decreased). As the transitional flow regime became negligible in the $11.5 \mathrm{~mm}$ test section when the flow was fully developed (Fig. 7(e) and (f)), the transition gradient was expected to tend to infinity $\left(T G_{j} \rightarrow \infty\right)$. However, this was not the case as the changes in the $y$-scale (Colburn $j$-factor) were much smaller than the changes in the $x$-scale (Reynolds number). Although the transition gradient was very small, $7.03 \times 10^{-5}$, it was still 14.8 times more than the forced convection case in the $4 \mathrm{~mm}$ test section. It was not experimentally possible to obtain a Reynolds number increment of less than 35 , and the transition gradient will only tend to infinity if the Reynolds number increment tends to zero. 


\subsubsection{Summary}

To summarise the effect of free convection on the heat transfer coefficients in the different flow regimes, the Colburn $j$-factors as a function of Reynolds number are compared in Fig. 13 for different heat fluxes, at $x / D=873$ in the $4 \mathrm{~mm}$ test section and at $x / D=802$ in the $11.5 \mathrm{~mm}$ test section. Furthermore, the effect of free convection on the heat transfer coefficients in the different flow regimes are schematically illustrated in Fig. 14. Points A to $\mathrm{N}$ in Fig. 13 correspond to the labels used in Fig. 14. The results at a heat flux of $1 \mathrm{~kW} / \mathrm{m}^{2}$ in the $4 \mathrm{~mm}$ test section in Fig. 13 (line A-B-C), and the solid black line A-B-C-D-E in Fig. 14, represents forced convection conditions, therefore the Grashof numbers were the lowest. As the heat flux was increased to $3 \mathrm{~kW} / \mathrm{m}^{2}$ in the $4 \mathrm{~mm}$ test section (line F-G-H-D), the Grashof numbers increased, and it increased further when the tube diameter was increased to $11.5 \mathrm{~mm}$. Therefore, the maximum Grashof numbers were obtained at a heat flux of $3 \mathrm{~kW} / \mathrm{m}^{2}$ in the $11.5 \mathrm{~mm}$ test section (line L-M-N-D-E).

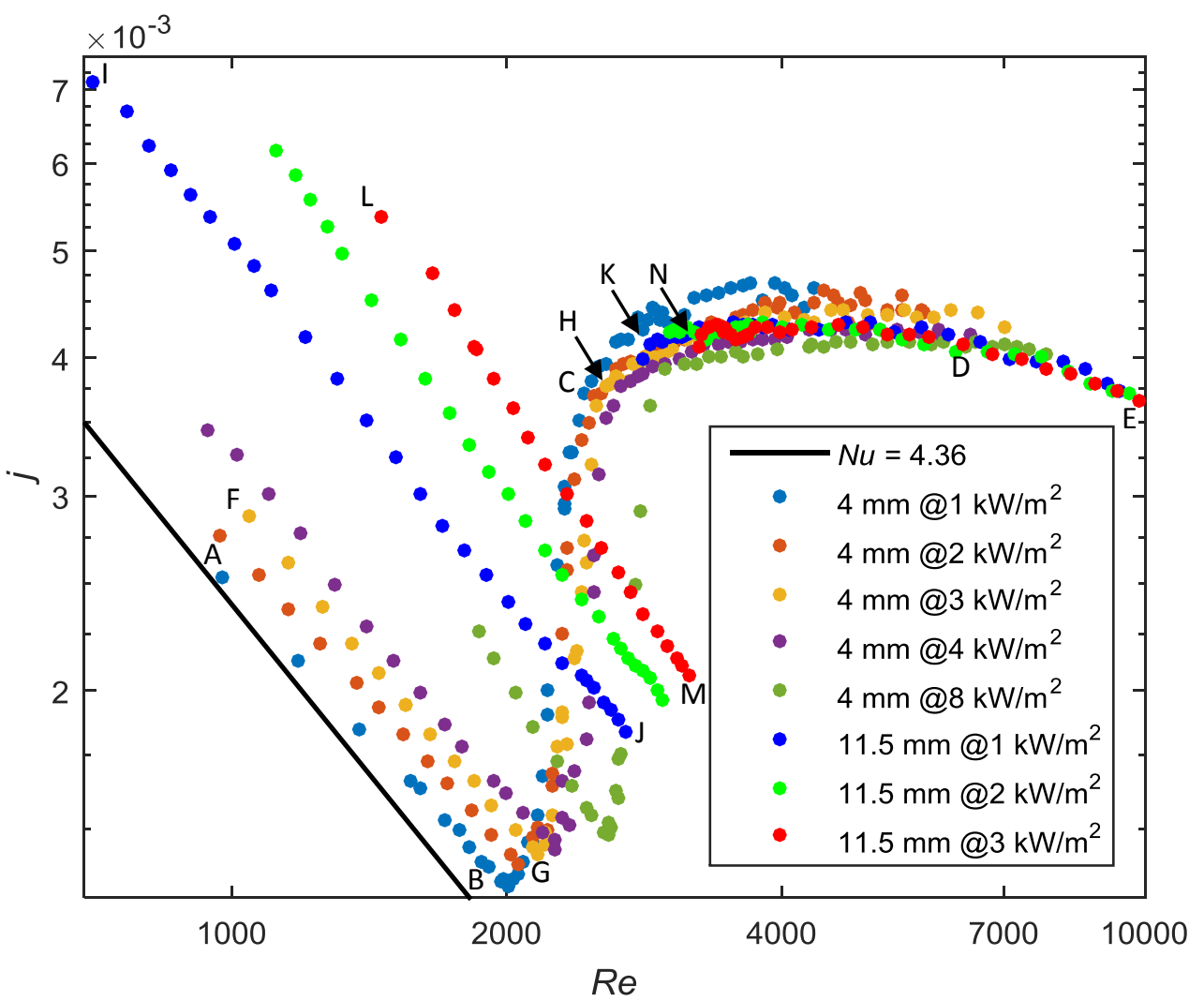

Fig. 13: Comparison of Colburn j-factors as a function of Reynolds number for different heat fluxes in the $4 \mathrm{~mm}$ and $11.5 \mathrm{~mm}$ test sections.

From Fig. 13 it follows that as free convection effects (and thus Grashof number) were increased, due to increasing heat flux (lines A-B and F-G) and tube diameter (lines I-J and L$\mathrm{M})$, the magnitude of the laminar Colburn $j$-factors increased, and $(d j / d R e)_{L}$ decreased. From points $\mathrm{B}$ and $\mathrm{G}$ it follows that the start of transition, $R e_{c r}$, was delayed from a Reynolds 
number of 2005 to 2163 when the heat flux was increased from $1 \mathrm{~kW} / \mathrm{m}^{2}$ to $3 \mathrm{~kW} / \mathrm{m}^{2}$ in the $4 \mathrm{~mm}$ test section, due to the decreasing viscosity with increasing temperature. From points $\mathrm{G}$ and $\mathrm{M}$ it follows that, at a fixed heat flux of $3 \mathrm{~kW} / \mathrm{m}^{2}$, transition was also significantly delayed from a Reynolds number of 2163 to 3176 , as the tube diameter was increased from $4 \mathrm{~mm}$ to $11.5 \mathrm{~mm}$. The critical Reynolds number therefore increased with increasing Grashof number (free convection effects), as indicated by points B, G, J, M and P in Fig. 14.

Free convection effects caused the flow inside the test section to transition faster from laminar to turbulent. Therefore, as the heat flux and tube diameter (Grashof number) was increased, the transition gradient $\left((d j / d R e)_{T G}\right)$ increased from $6.9 \times 10^{-6}$ at a heat flux of $1 \mathrm{~kW} / \mathrm{m}^{2}$ in the $4 \mathrm{~mm}$ test section (line B-C), to $6.1 \times 10^{-5}$ at a heat flux of $3 \mathrm{~kW} / \mathrm{m}^{2}$ in the $11.5 \mathrm{~mm}$ test section (line $\mathrm{M}-\mathrm{N})$, and the width of the transitional flow regime $(\Delta R e)$ decreased from a Reynolds number range of 873 to 35 . When the Grashof number was high enough, as in the $11.5 \mathrm{~mm}$ test section, the transitional flow regime became negligible when the flow was fully developed. The flow alternated between the laminar and quasi-turbulent flow regimes, stabilising as laminar at the critical Reynolds number (point $\mathrm{M}$ ) and in the quasi-turbulent flow regime at the next Reynolds number increment (point $\mathrm{N}$ ), skipping the entire transitional flow regime.

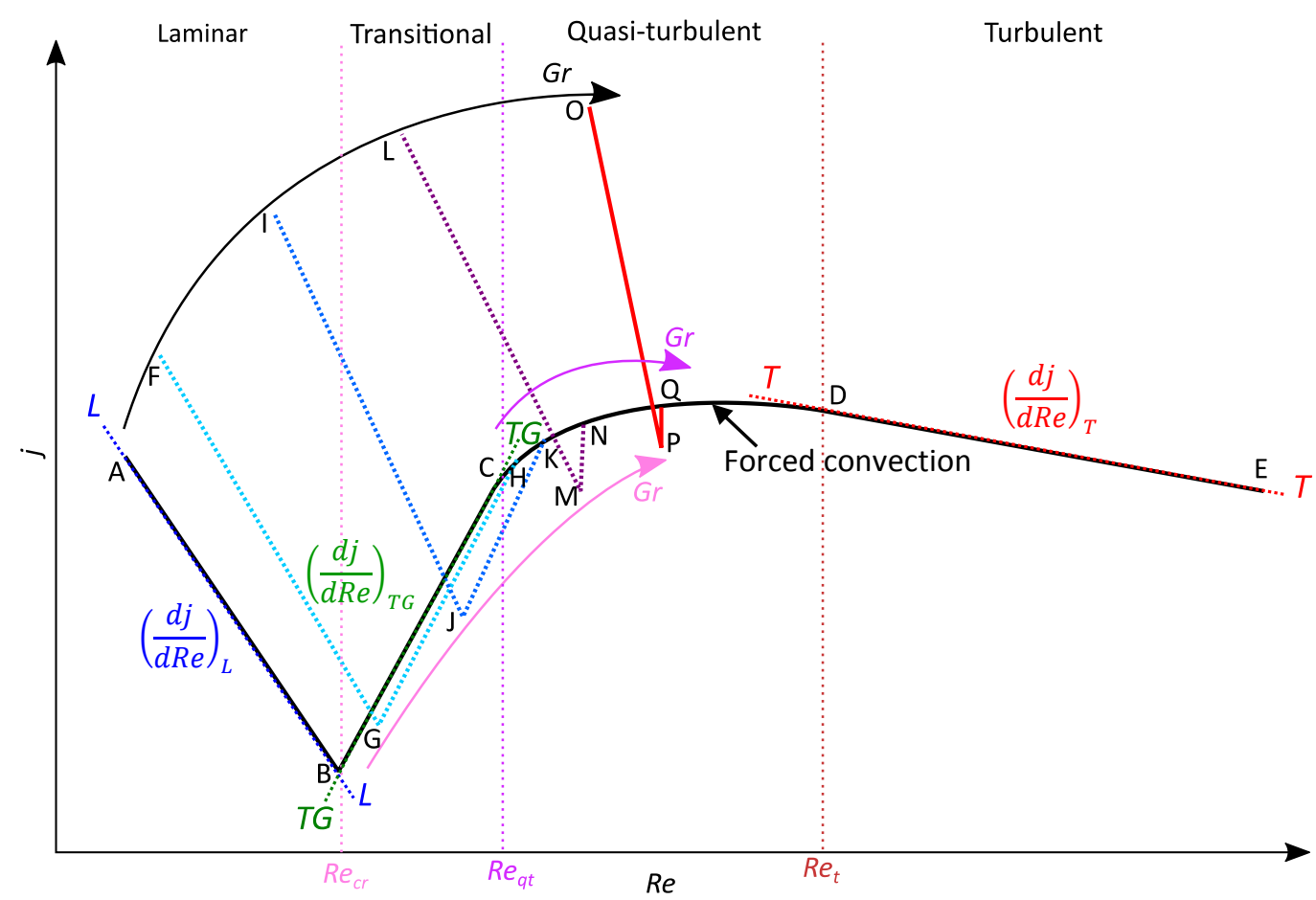

Fig. 14: Schematic representation of the influence of Grashof number on the different flow regime when the heat transfer coefficients are investigated in terms of the Colburn $j$-factor as a function of Reynolds number. 
From points $\mathrm{C}, \mathrm{H}, \mathrm{K}$ and $\mathrm{N}$ in Fig. 13, it follows that the end of the transitional flow regime, $R e_{q t}$, was delayed with increased heat flux and tube diameter (thus Grashof number in Fig. 14). As expected, the turbulent flow regime was unaffected by heat flux or tube diameter, since the free convection effects were suppressed by the velocity of the fluid. The flow became fully turbulent, $R e_{t}$, at approximately the same Reynolds number of 6000 (point D). As the start of the quasi-turbulent flow regime, $R e_{q t}$, was delayed, while the start of the turbulent flow regime was unaffected, the width of the quasi-turbulent flow regime decreased with increasing free convection effects. It can therefore be postulated that if the Grashof number is significantly increased and tends to infinity (line O-P-Q-D-E in Fig. 14), the width of both the transitional and quasi-turbulent flow regimes might become negligible for fully developed flow. Therefore, the flow regime might change from laminar to fully turbulent without any noteworthy transitional and quasi-turbulent flow regimes.

\subsection{Influence of Prandtl number}

Ghajar and co-workers did the pioneering work on transitional flow, investigating the effects of heat flux and inlet geometries. Strickland, a masters student of Professor Ghajar, did the heat transfer experiments using a square-edged inlet [46]. Three different test fluids were used and the ranges of the experiments conducted with each test fluid are summarised in Table 2. From this table it follows that pure ethylene glycol and distilled water was used for the laminar and turbulent flow regimes, respectively, while a mixture of $60 \%$ ethylene glycol (by mass fraction) and water was used for the transitional flow regime, as well as part of the laminar and quasi-turbulent flow regimes. As their focus was on fully developed flow, and to avoid any entrance effects, the data at $x / D=192$ (station 22) was mainly used to investigate the heat transfer characteristics in the transitional flow regime (although the test section contained 31 thermocouple stations).

Table 2: Summary of experimental data of Strickland [46].

\begin{tabular}{cccc}
\hline & Distilled water & $60 \%$ ethylene glycol & $100 \%$ ethylene glycol \\
\hline$R e$ & $3639-50529$ & $1180-12456$ & $280-3328$ \\
$P r$ & $3.44-6.24$ & $16.8-55.29$ & $95.89-157.8$ \\
$N u$ & $31.3-232$ & $12.9-146.3$ & $15-80.2$ \\
$G r$ & $6.3 \times 10^{4}-2.3 \times 10^{6}$ & $2.6 \times 10^{3}-2 \times 10^{5}$ & $1 \times 10^{3}-1.6 \times 10^{4}$ \\
$\dot{q}\left[\mathrm{~kW} / \mathrm{m}^{2}\right]$ & $13.5-62.8$ & $4.8-57.9$ & $6.1-28.8$ \\
\hline
\end{tabular}

To investigate the effect of Prandtl number and tube diameter, Fig. 15 compares the results of Strickland [46] to the results of this study at $x / D \approx 176$ and $x / D \approx 219$ in the $4 \mathrm{~mm}$ and $11.5 \mathrm{~mm}$ test sections. These stations were chosen since it was the closest to $x / D=192$, 
which was used by Strickland [46]. The results of Strickland were obtained at different heat fluxes and are indicated by the square markers, while the results in the $4 \mathrm{~mm}$ and $11.5 \mathrm{~mm}$ test sections were obtained at a heat flux of $3 \mathrm{~kW} / \mathrm{m}^{2}$, and are indicated by the empty and filled circles, respectively.

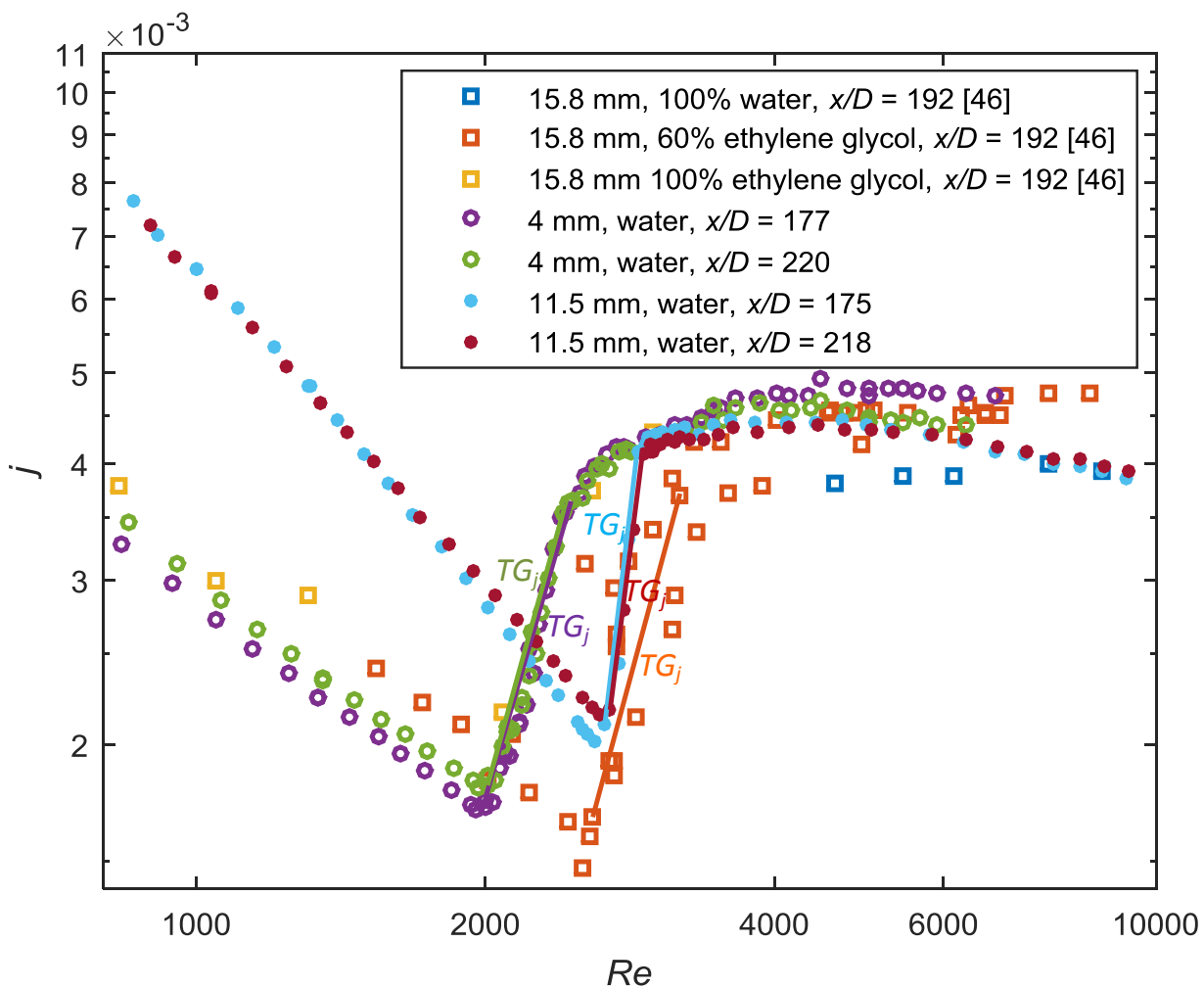

Fig. 15: Comparison of the Colburn j-factor as a function of Reynolds number of the experimental data of Strickland [46] at $x / D=192$, with the experimental data of this study at $x / D=177$ and $x / D=220$ in the $4 \mathrm{~mm}$ test section, and at $x / D=175$ and $x / D=218$ in the $11.5 \mathrm{~mm}$ test section. The solid lines illustrate the transition gradient of each experimental data set.

Although the laminar data of Strickland [46] was obtained at different heat fluxes $\left(4.9 \mathrm{~kW} / \mathrm{m}^{2}\right.$ to $\left.28.8 \mathrm{~kW} / \mathrm{m}^{2}\right)$, it follows from Fig. 15 that, unlike the results of Fig. 13, the laminar heat transfer coefficients were not significantly affected. This is due to the difference in the fluid properties of water and ethylene glycol. When the fluid properties of water $(\operatorname{Pr} \approx 7)$ and ethylene glycol $(\operatorname{Pr} \approx 100)$ were investigated between temperatures of $20^{\circ} \mathrm{C}$ and $80^{\circ} \mathrm{C}$, it was found that the specific heat and thermal conductivity of ethylene glycol were up to $50 \%$ and $60 \%$, respectively, less than water, which led to greater temperature differences. However, the density was $12 \%$ higher, and the viscosity an order of magnitude higher, than that of water. As the viscosity of ethylene glycol is a strong function of temperature, free convection effects were significant, but were restricted to the thermal boundary layer (higher temperature and lower viscosity), due to the significantly higher viscosity in the centre of the tube. Therefore, free convection effects could not lead to significant secondary flow, that 
assisted in distributing the heat from the surface to the centre of the tube, and significantly increase the heat transfer coefficients. From Fig. 15 it also follows that there was no significant discontinuity between the $100 \%$ ethylene glycol and $60 \%$ ethylene glycol results in the laminar flow regime, since both test fluids had high viscosities which restricted free convection effects to the thermal boundary layer.

From Fig. 15 it also follows that free convection effects led to a decreased laminar Colburn $j$-factor gradient when the tube diameter was increased from $4 \mathrm{~mm}$ to $11.5 \mathrm{~mm}$. Although the tube diameter used by Strickland [46] was 1.37 times and 3.97 times larger than the $11.5 \mathrm{~mm}$ and $4 \mathrm{~mm}$ test sections, respectively, free convection effects were suppressed by the significantly higher viscosity of ethylene glycol. In the $4 \mathrm{~mm}$ test section, the laminar Colburn $j$-factors increased between $x / D=176$ and $x / D=219$, since free convection effects increased with increasing thermal boundary layer thickness. However, the difference between the two stations in the $11.5 \mathrm{~mm}$ test section was negligible at Reynolds numbers less than 2000 , since the increased free convection effects caused the thermal boundary layer thickness to develop significantly faster.

Transition occurred first in the $4 \mathrm{~mm}$ test section at Reynolds numbers of 1959 and 1971 , then in Strickland's test section at a Reynolds number of 2 524, and last in the $11.5 \mathrm{~mm}$ test section at Reynolds numbers of 2602 and 2 637. From Fig. 11(a) it was concluded that the critical Reynolds number increased with increasing heat flux and tube diameter. However, the increased viscosity of ethylene glycol caused the critical Reynolds number Strickland's test section to decrease compared to the $11.5 \mathrm{~mm}$ test section.

The solid lines in Fig. 15 indicate the transition gradients of each test section. Due to the different heat fluxes and test fluids which were used by Strickland [46], scatter existed in the transitional flow regime, which made it challenging to determine the transition gradient. However, it was estimated to be $3.38 \times 10^{-6}$, while the transition gradients of the $4 \mathrm{~mm}$ and $11.5 \mathrm{~mm}$ test sections were approximately $4.25 \times 10^{-6}$ and $9.13 \times 10^{-6}$, respectively. Increased free convection effects led to an increased transition gradient when the tube diameter was increased from $4 \mathrm{~mm}$ to $11.5 \mathrm{~mm}$, however, there was a negligible difference between the transition gradients of the two thermocouple stations in each test section. The increased viscosity of $60 \%$ ethylene glycol, led to decreased free convection effects, therefore the flow transitioned slower from laminar to turbulent, causing the transition gradient to decrease, and the width of the transitional flow regime to increase.

The results of the $4 \mathrm{~mm}$ and $11.5 \mathrm{~mm}$ test sections in the quasi-turbulent and turbulent flow regimes, compared fairly well with the results of Strickland [46]. As free convection 
effects were suppressed by the velocity of the fluid, the heat transfer coefficients were independent of fluid properties, heat flux and tube diameter. Some scatter and discontinuities were expected in the turbulent flow regime, since the temperature differences decreased, which in turn led to increased uncertainties.

\subsection{Correlations: start and end of the transitional flow regime}

Ghajar and Tam [6] developed the following correlations to predict the start and end of the transitional flow regime for a square-edged inlet:

$$
\begin{aligned}
& R e_{c r}=2524-0.82\left(192-\frac{x}{D}\right) \\
& R e_{q t}=8791-7.69\left(192-\frac{x}{D}\right)
\end{aligned}
$$

As these equations were developed for $x / D$ values between 3 and 192, the start and end of transition was predicted to be at Reynolds numbers of 2369 - 2524 and 7337 - 8791 , respectively, for $3 \leq x / D \leq 192$. The result is that $\Delta R e$ varied between a Reynolds number range of 4968 and 6267 . When comparing these predictions to the results in Fig. 11, it was found that Eq. (28) predicted $R e_{c r}$ in the $11.5 \mathrm{~mm}$ test section within $4.5 \%$, but overpredicted $R e_{c r}$ in the $4 \mathrm{~mm}$ test section with $26 \%$. As Eq. (29) significantly overpredicted $R e_{q t}$ in both test sections, $\Delta R e$ was also significantly overpredicted.

From Fig. 11(a) it was concluded that both the start and end of the transitional flow regime were influenced by axial position and free convection effects. As Eqs. (28) and (29) are a function of axial position only, and do not account for any free convection effects, correlations were developed for a square-edged inlet that account for both axial position $(x / D)$ and free convection effects ( $G r$ and $\left.G r^{*}\right)$.

The critical Reynolds number was divided by $G r^{0.077}$ to account for mixed convection conditions, and plotted against axial position in Fig. 16(a). A linear trend line was fitted through the data points to obtain the following correlation:

$$
R e_{c r}=\left(0.1972 \frac{x}{D}+1156.7\right) G r^{0.077}
$$




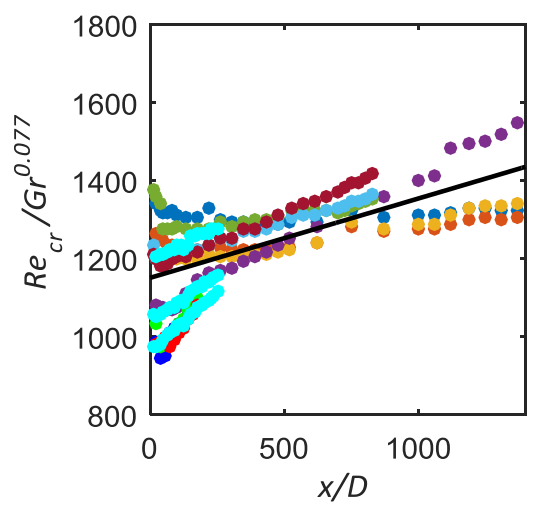

(a)

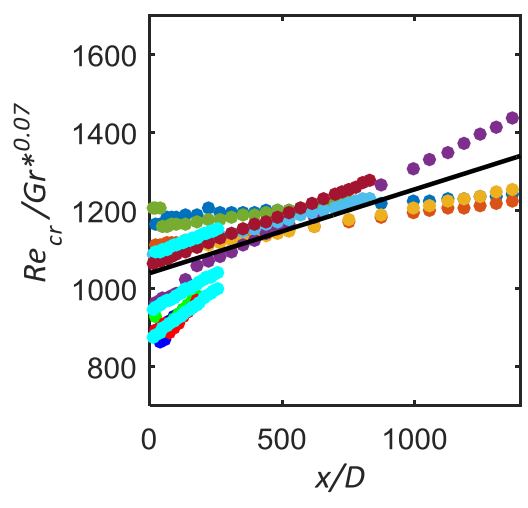

(c)

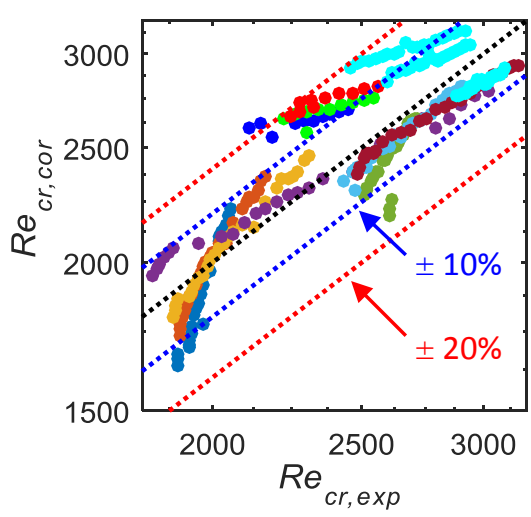

(b)

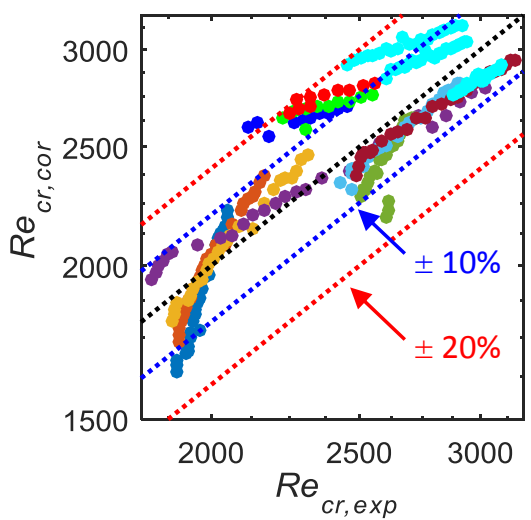

(d)

Fig. 16: Comparison of (a) $R e_{c r} / G r^{0.077}$ and (c) $R e_{c r} / G r^{* 0.07}$ as a function of axial position, deviation between (b) Eq. (30) and (d) Eq. (31) and experimental data and literature.

From Eq. (30) it follows that the critical Reynolds number increased linearly along the test section (as was found in Fig. 11(a) due to the decreasing viscosity with temperature) and the gradient of the line was influenced by the Grashof number, thus free convection effects. To develop a correlation that is a function of heat flux and not temperature difference, the following correlation in terms of the modified Grashof number, was obtained from Fig. 16(c):

$$
R e_{c r}=\left(0.209 \frac{x}{D}+1044.4\right) G r^{* 0.07}
$$

The Reynolds number at which transition ended $\left(R e_{q t}\right)$ was divided by the Grashof number to account for mixed convection conditions, and the results $\left(\operatorname{Re}_{q t} / G r\right)$ were plotted against Grashof number in Fig. 17(a). It was found that it was not necessary to include the axial position $(x / D)$, since the Grashof number is a function of tube location (temperature difference and thermal properties vary along the tube length). A power curve fit was done through the data points to obtain the following correlation: 


$$
\frac{R e_{q t}}{G r}=2504 G r^{-0.982}
$$

and thus

$$
R e_{q t}=2504 G r^{0.018}
$$

Similarly, a correlation was developed in terms of the modified Grashof number (Fig. 17(c)):

$$
\begin{aligned}
\frac{R e_{q t}}{G r^{*}} & =2313.2 G r^{*-0.98} \\
R e_{q t} & =2312.2 G r^{* 0.02}
\end{aligned}
$$

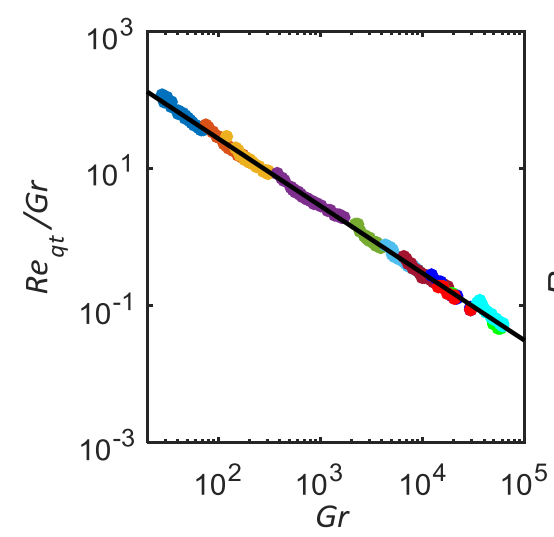

(a)

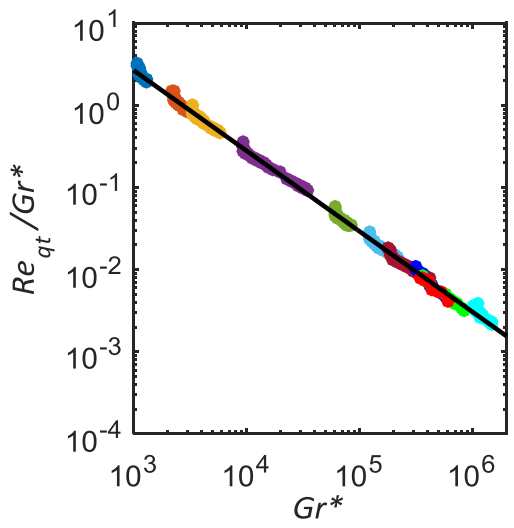

(c)

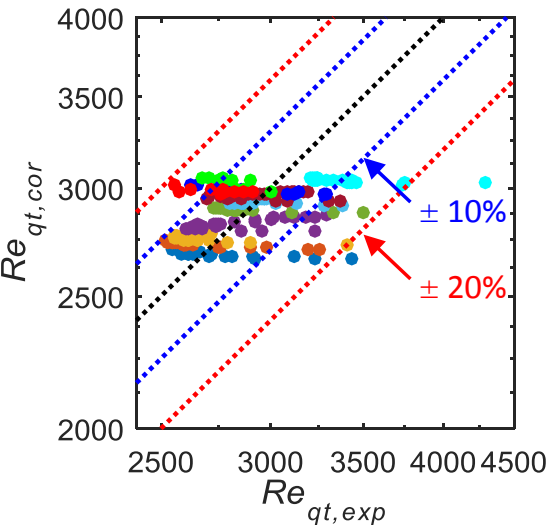

(b)

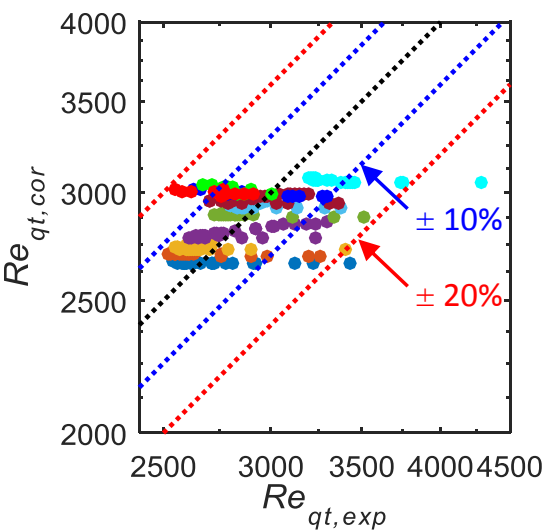

(d)

Fig. 17: Comparison of (a) $R e_{q t} / G r$ as a function of Grashof number, (b) deviation between Eq. (33) and experimental data and literature, (c) $R e_{q t} / G r^{*}$ as a function of modified Grashof number and (d) deviation between Eq. (35) and experimental data and literature.

Eqs. (30), (31), (33) and (35) were compared to experimental results of this study and literature, and the performance and ranges of the correlations are summarised in Table 3. From this table it follows that the $R e_{c r}$ correlations were able to predict $80 \%$ the data within 
$10 \%$, and approximately all the data within $20 \%$. The $R e_{q t}$ correlations were able to predict $85 \%$ the data within $10 \%$, and the average deviation was approximately $6 \%$.

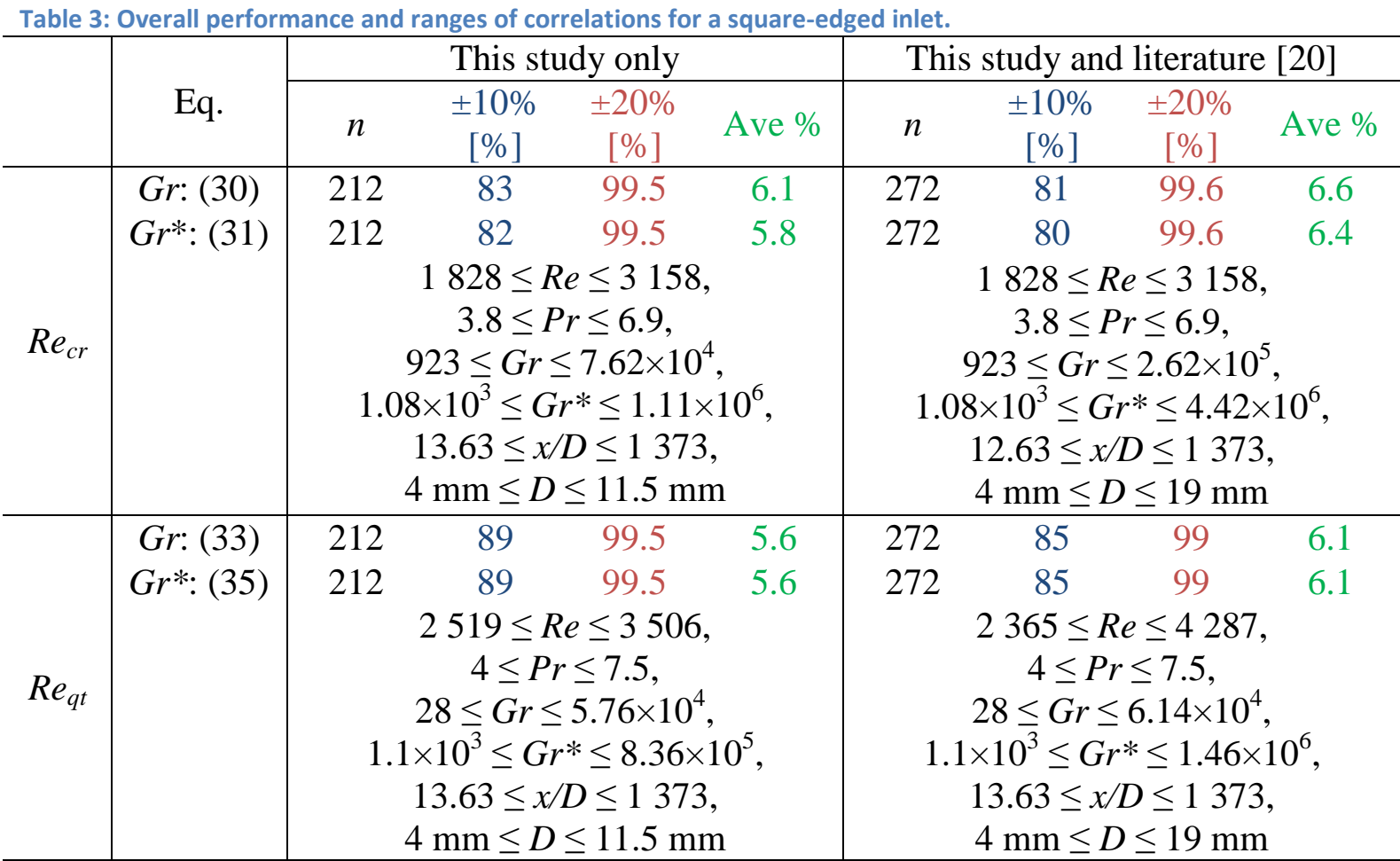

\section{Conclusions}

Up to now, no experimental work has been done, specifically focussing on how the heat transfer characteristics of developing flow in the transitional flow regime changes along the tube length, how it compares with fully developed flow, and how it is affected by free convection effects. Furthermore, although the boundaries of the transitional flow regime have been described in literature, the descriptions were qualitatively and relied on visual observations, which are subjective. In most of the cases, no clear distinction between the transitional and quasi-turbulent flow regimes was made either. The purpose of this study was therefore to experimentally investigate the influence of axial position, free convection effects and Prandtl number on the heat transfer characteristics of developing and fully developed flow in smooth tubes in the transitional flow regime. The Reynolds number was varied between 700 and 10000 to ensure that the transitional and quasi-turbulent flow regimes, as well as sufficient parts of the laminar and turbulent flow regimes, were covered. The boundaries between the flow regimes were defined mathematically, and terminology to define transitional flow characteristics were presented.

The local Reynolds numbers, Nusselt numbers, Colburn $j$-factors and Grashof numbers were calculated at each of the 27 thermocouple stations, in both test sections, and then 
compared with each other. It was found that the Reynolds number at which transition started was independent of axial position for both developing and fully developed flow, and transition occurred at the same moment in time along the whole tube length. However, the end of transition was dependent of axial position when the flow was developing and occurred earlier as the flow approached fully developed flow. Once the flow was fully developed, the end of transition became independent of axial position. Free convection effects affected both the start and end of the transitional flow regime, and caused the Reynolds number range of the transitional flow regime to decrease. Correlations were developed to determine the start and end of the transitional flow regime for developing and fully developed flow in mixed convection conditions.

The transitional flow regime across the tube length was divided into three regions. In the first region, the width of the transitional flow regime decreased significantly with axial position as the thermal boundary layer thickness increased, and free convection effects were negligible. In region 2 , the width of the transitional flow regime decreased with axial position, due to the development of the thermal boundary layer, as well as with free convection effects. In the fully developed region (region 3), the width of the transitional flow regime was independent of axial position, but decreased significantly with increasing free convection effects. At high Grashof numbers, free convection effects even caused the transitional flow regime to become negligible when the flow was fully developed, and the flow alternated between the laminar and the quasi-turbulent flow regimes. It was concluded that the heat transfer characteristics of developing flow in the transitional flow regime changes as the flow develops, and differ significantly from fully developed flow, especially when mixed convection conditions exist.

\section{Acknowledgements}

The funding obtained in South Africa from the NRF, Stellenbosch University/ University of Pretoria Solar Hub, CSIR, EEDSM Hub, RDP and NAC is acknowledged and duly appreciated. The authors would also like to thank Professor A.J. Ghajar from Oklahoma State University, for making the experimental data of Strickland [46] available, as well for his fruitful discussion at the HEFAT2016 conference in Malaga, Spain. This work was produced as part of a $\mathrm{PhD}$ in mechanical engineering at the University of Pretoria by the first author under the supervision of the second author. 


\section{References}

[1] L.M. Tam, Transitional heat transfer in plain horizontal tubes, Heat Transfer Eng, 27(5) (2006) 23-38.

[2] J.P. Meyer, Heat transfer in tubes in the transitional flow regime, in: 15th International Heat Transfer Conference, Kyoto, Japan, 2014.

[3] A.J. Ghajar, L.M. Tam, Laminar-transition-turbulent forced and mixed convective heat transfer correlations for pipe flows with different inlet configurations, in: Winter Annual Meeting of the American Society of Mechanical Engineers, Publ by ASME, New York, United States, 1991, pp. 15-23.

[4] A.J. Ghajar, K.F. Madon, Pressure drop measurements in the transition region for a circular tube with three different inlet configurations, Exp. Therm. Fluid Sci., 5(1) (1992) 129-135.

[5] A.J. Ghajar, L.M. Tam, Heat transfer measurements and correlations in the transition region for a circular tube with three different inlet configurations, Exp. Therm. Fluid Sci., 8(1) (1994) 79-90.

[6] A.J. Ghajar, L.M. Tam, Flow regime map for a horizontal pipe with uniform wall heat flux and three inlet configurations, Exp. Therm. Fluid Sci., 10(3) (1995) 287-297.

[7] L.M. Tam, A.J. Ghajar, Effect of Inlet Geometry and Heating on the Fully Developed Friction Factor in the Transition Region of a Horizontal Tube, Exp. Therm. Fluid Sci., 15(1) (1997) 52-64.

[8] L.M. Tam, A.J. Ghajar, The unusual behavior of local heat transfer coefficient in a circular tube with a bell-mouth inlet, Exp. Therm. Fluid Sci., 16(3) (1998) 187-194.

[9] A.J. Ghajar, C.C. Tang, W.L. Cook, Experimental investigation of friction factor in the transition region for water flow in minitubes and microtubes, Heat Transfer Eng, 31(8) (2010) 646-657.

[10] H.K. Tam, L.M. Tam, A.J. Ghajar, S.C. Tam, T. Zhang, Experimental investigation of heat transfer, friction factor, and optimal fin geometries for the internally microfin tubes in the transition and turbulent regions, J. Enhanced Heat Transf., 19(5) (2012) 457-476.

[11] H.K. Tam, L.M. Tam, A.J. Ghajar, Effect of inlet geometries and heating on the entrance and fully-developed friction factors in the laminar and transition regions of a horizontal tube, Exp. Therm. Fluid Sci., 44 (2013) 680-696.

[12] L.M. Tam, H.K. Tam, A.J. Ghajar, W.S. Ng, C.K. Wu, The effect of inner surface roughness and heating on friction factor in horizontal mini-tubes, in: 15th International Heat Transfer Conference, Kyoto, Japan, 2014.

[13] J.A. Olivier, J.P. Meyer, Single-phase heat transfer and pressure drop of the cooling of water inside smooth tubes for transitional flow with different inlet geometries (RP-1280), HVAC R Res, 16(4) (2010) 471-496.

[14] J.P. Meyer, J.A. Olivier, Transitional flow inside enhanced tubes for fully developed and developing flow with different types of inlet disturbances: Part II-heat transfer, Int. J. Heat Mass Transf., 54(7-8) (2011) 1598-1607.

[15] J.P. Meyer, J.A. Olivier, Transitional flow inside enhanced tubes for fully developed and developing flow with different types of inlet disturbances: Part I - Adiabatic pressure drops, Int. J. Heat Mass Transf., 54(7-8) (2011) 1587-1597.

[16] J.P. Meyer, J.A. Olivier, Heat transfer and pressure drop characteristics of smooth horizontal tubes in the transitional flow regime, Heat Transfer Eng, 35(14-15) (2014) 12461253.

[17] J.P. Meyer, T.J. McKrell, K. Grote, The influence of multi-walled carbon nanotubes on single-phase heat transfer and pressure drop characteristics in the transitional flow regime of smooth tubes, Int. J. Heat Mass Transf., 58(1-2) (2013) 597-609. 
[18] J. Dirker, J.P. Meyer, D.V. Garach, Inlet flow effects in micro-channels in the laminar and transitional regimes on single-phase heat transfer coefficients and friction factors, Int. J. Heat Mass Transf., 77(0) (2014) 612-626.

[19] D.D. Ndenguma, J. Dirker, J.P. Meyer, Transitional flow regime heat transfer and pressure drop in an annulus with non-uniform wall temperatures, Int. J. Heat Mass Transf., 108 (2017) 2239-2252.

[20] J.P. Meyer, S.M. Abolarin, Heat transfer and pressure drop in the transitional flow regime for a smooth circular tube with twisted tape inserts and a square-edge inlet, Int. J. Heat Mass Transf., 117 (2018) 11-29.

[21] D. Bertsche, P. Knipper, T. Wetzel, Experimental investigation on heat transfer in laminar, transitional nd turbulent circular pipe flow, Int. J. Heat Mass Transf., 95 (2016) 1008-1018.

[22] V. Gnielinski, On heat transfer in tubes, Int. J. Heat Mass Transf., 63 (2013) 134-140.

[23] D. Taler, A new heat transfer correlation for transition and turbulent fluid flow in tubes, Int. J. Therm. Sci., 108 (2016) 108-122.

[24] V. Gnielinski, New equations for heat and mass-transfer in turbulent pipe and channel flow, International Chemical Engineering, 16(2) (1976) 359-368.

[25] S.W. Churchill, Comprehensive correlating equations for heat, mass and momentum transfer in fully developed flow in tubes, Industrial Engineering Chemistry Fundamentals, 16(1) (1977) 109-116.

[26] W. Yu-ting, L. Bin, M. Chong-fang, G. Hang, Convective heat transfer in the laminarturbulent transition region with molten salt in a circular tube, Exp. Therm. Fluid Sci., 33(7) (2009) 1128-1132.

[27] J. Lu, S. He, J. Liang, J. Ding, J. Yang, Convective heat transfer in the laminar-turbulent transition region of molten salt in annular passage, Exp. Therm. Fluid Sci., 51 (2013) 71-76.

[28] J.P. Abraham, E.M. Sparrow, W.J. Minkowycz, Internal-flow Nusselt numbers for the low-Reynolds-number end of the laminar-to-turbulent transition regime, Int. J. Heat Mass Transf., 54(1-3) (2011) 584-588.

[29] D. Taler, A. Korzeń, Numerical Modeling of Transient Operation of a Plate Fin and Tube Heat Exchanger at Transition Fluid Flow in Tubes, in: A. Mohamad, A.C. Benim, J. Taler (Eds.) 9th International Conference on Computational Heat and Mass Transfer, ICCHMT 2016, Elsevier Ltd, 2016, pp. 163-170.

[30] M. Everts, J.P. Meyer, Relationship between pressure drop and heat transfer of developing and fully developed flow in smooth horizontal circular tubes in the laminar, transitional, quasi-turbulent and turbulent flow regimes, Int. J. Heat Mass Transf., (2017), Manuscript nr: HMT_2017_2233, submitted on 7 June 2017.

[31] J.P. Meyer, M. Everts, Single-phase mixed convection of developing and fully developed flow in smooth horizontal circular tubes in the laminar and transitional flow regimes, Int. J. Heat Mass Transf., (2017), Manuscript nr: HMT_2017_2231, submitted on 7 June 2017.

[32] M. Everts, J.P. Meyer, Flow regime maps for smooth horizontal tubes at a constant heat flux, Int. J. Heat Mass Transf., (2017), Manuscript nr: HMT_2017_2234, submitted on 7 June 2017.

[33] M. Everts, Single-phase mixed convection of developing and fully developed flow in smooth horizontal circular tubes in the laminar, transitional, quasi-turbulent and turbulent flow regimes, $\mathrm{PhD}$ thesis, University of Pretoria, Pretoria, 2017 (under examination).

[34] L.M. Tam, A.J. Ghajar, H.K. Tam, S.C. Tam, Development of a flow regime map for a horizontal pipe with the multi-classification Support Vector Machines, in: 2008 Proceedings of the ASME Summer Heat Transfer Conference, HT 2008, 2009, pp. 537-547. 
[35] H.K. Tam, L.M. Tam, A.J. Ghajar, C.W. Cheong, Development of a unified flow regime map for a horizontal pipe with the support vector machines, in: AIP Conference Proceedings, 2010, pp. 608-613.

[36] F. Bozzoli, L. Cattani, S. Rainieri, Effect of wall corrugation on local convective heat transfer in coiled tubes, Int. J. Heat Mass Transf., 101 (2016) 76-90.

[37] F. Bozzoli, L. Cattani, S. Rainieri, F.S. Viloche Bazán, L.S. Borges, Estimation of the local heat-transfer coefficient in the laminar flow regime in coiled tubes by the Tikhonov regularisation method, Int. J. Heat Mass Transf., 72 (2014) 352-361.

[38] G. Maranzana, I. Perry, D. Maillet, Mini- and micro-channels: influence of axial conduction in the walls, Int. J. Heat Mass Transf., 47(17) (2004) 3993-4004.

[39] A. Bakker, R.D. LaRoche, E.M. Marshall, Laminar flow in static mixers with helical elements, in: The Online CFM Book, 2000.

[40] C.O. Popiel, J. Wojtkowiak, Simple formulas for thermophysical properties of liquid water for heat transfer calculations [from $\mathrm{O}^{\circ} \mathrm{C}$ to $150^{\circ} \mathrm{C}$ ], Heat Transfer Eng, 19(3) (1998) 87-101.

[41] W. Giedt, Investigation of variation of point unit heat-transfer coefficient around a cylinder normal to an air stream, Trans. ASME, 71(375-381) (1949) 147.

[42] P.F. Dunn, Measurement and Data Analysis for Engineering and Science, 2nd ed., CRC Press, United States of America, 2010.

[43] R.K. Shah, A.L. London, Laminar Flow Forced Convection in Ducts, Academic Press, New York, 1978.

[44] S.M. Morcos, A.E. Bergles, Experimental investigation of combined forced and free laminar convection in horizontal tubes, Journal of Heat Transfer, 97(2) (1975) 212-219.

[45] Y.A. Cengel, Heat and Mass Transfer: A Practical Approach, 3rd ed., McGraw-Hill, Singapore, 2006.

[46] D.T. Strickland, Heat transfer measurements in the transition region for a horizontal circular tube with a square-edged entrance, Masters dissertation, Oklahoma State University, Stillwater, 1990. 